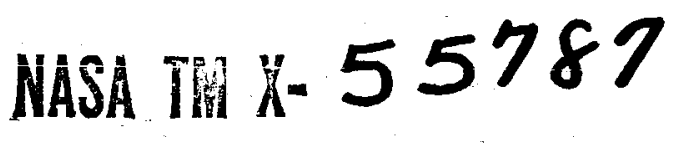

\section{A LATITUDE SURVEY OF THE EQUATORIAL ELECTROJET WITH ROCKET-BORNE MAGNETOMETERS}

\section{GPO PRICE $\$$}

CFSTI PRICE(S) S

Hard copy $(\mathrm{HC})$
Microfiche (MF)

BY

$\frac{\$ 3.00}{.65}$

T. N. DAVIS, K. BURROWS

J. D. STOLARIK
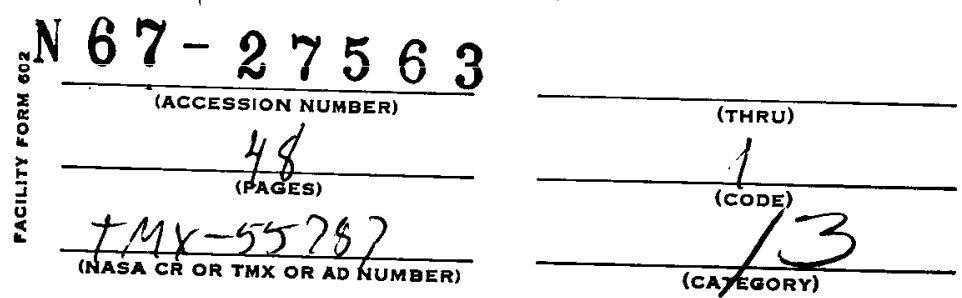

JULY 1966 


\title{
A LATITUDE SURVEY OF THE EQUATORIAL ELECTROJET \\ WITH ROCKET-BORNE MAGNETOMETERS \\ by
}

\author{
T. N. Davis* \\ K. Burrows** \\ and \\ J. D. Stolarik \\ NASA-Goddard Space Flight Center, \\ Greenbelt, Maryland
}

\footnotetext{
*Now at Geophysical Institute, University of Alaska, College, Alaska

**NAS-NASA Resident Research Associate at Goddard Space Flight Center, Greenbelt, Maryland
} 


\begin{abstract}
Experimentally determined profiles of ionospheric current density within and near the equatorial electrojet have been derived from measurements of total magnetic field. The field measurements were obtained from rocket-borne rubidium vapor magnetometers launched near the coast of Peru during March 1965. A normalized latitudinal cross-section of ionospheric current density has been obtained using the results of 9 rocket flights distributed between 140 $\mathrm{km} \mathrm{S}$ to $1100 \mathrm{~km} \mathrm{~N}$ of the magnetic equator. The lower boundary of the equatorial electrojet is near altitude $87 \mathrm{~km}$. A steep vertical gradient in current density appeared near altitude $100 \mathrm{~km}$ and the maximum current density, $10 \mathrm{amp} / \mathrm{km}^{2}$, was measured at an altitude of $107 \mathrm{~km}$ directly above the measured location of the magnetic equator. The contour for the half-peak value of current density crosses the equator at altitudes of $102 \mathrm{~km}$ and $114 \mathrm{~km}$ and extends to $300 \mathrm{~km}$ north of the equator. The profile of current density near the magnetic equator suggests that the layer conductivity $\sigma_{\mathrm{xy}}$ as well as the layer conductivity $\sigma_{\mathrm{yy}}$ affects the electrojet configuration and also that the electrojet distorts the magnetic field sufficiently to affect the layer conductivities. Using observatory and rocket measurements the induced $\mathrm{H}$ component of the magnetic field was found to be 0.3 of the $\mathrm{H}$ contribution from the ionospheric current. A single nighttime rocket flight on the magnetic equator detected a very small ionospheric current opposite in direction to the eastward daytime electrojet.
\end{abstract}




\section{INTRODUCTION}

Eight Nike-Apache rockets carrying total field magnetometers were launched from the USNS Croatan in March 1965 as part of the NASA Mobile Launch Expedition to the coastal waters of Peru. Advantage was taken of the mobility of the launch platform to attempt to obtain a latitudinal cross-section of the equatorial electrojet by means of appropriately placed rocket flights. Among the considerations entering into the selection of locations and times of rocket launches were additional magnetometer flights by other investigators (Maynard and Cahill, 1965a) and rocket flights carrying other types of instrumentation. In particular, Aiken and Blumle (1965) launched rockets to measure electron density and electron temperature in conjunction with several of the magnetometer flights reported here.

Much information about the equatorial electrojet is already available from previous rocket flights (Singer, et al., 1951; Cahill, 1959 and Maynard and Cahill, 1965b) and from studies based on data from magnetic observatories and other knowledge. These include studies by Bartels and Johnston, 1950; Onwumechilli, 1959; Forbush and Casaverde, 1961; Rao and Raja Rao, 1963; and Sugiura and Cain, 1965.

\section{INSTRUMENTATION}

The primary instrument used in this study is the rubidium-vapor magnetometer (Bloom, 1962). In this magnetometer the Zeeman splitting of atomic energy levels in $\mathrm{Rb}^{85}$ vapor is detected as resonance absorption of light from a $\mathrm{Rb}^{85}$ 
source. The frequency of resonance, the Larmor frequency, is a direct measure of the total scalar magnetic field intensity by the relationship

$$
f(c p s)=466,755 F+(K) 359 F^{2}
$$

for a one-cell magnetometer where $F$ is in gauss and $\mathrm{K}$, usually $<0.5$, indicates the fraction of the constant with $\mathrm{F}^{2}$ that appears in a given instrument. Here a self-oscillating, cross-coupled dual arrangement is used to largely eliminate the $\mathrm{F}^{2}$ dependence so that the variation with orientation is small, less than \pm 2 gamma at $\mathrm{F}=0.5$ gauss. Dual- (or single-) cell rubidium magnetometers have null regions (regions of low signal amplitude) of conical shape centered on the instrument optical axis and in the form of a zone centered on the plane perpendicular to the optical axis. The instruments used here have conical nulls of half-angle near $10^{\circ}$ and zonal nulls of half-width $5^{\circ}$ or less.

Three magnetometer configurations were used in these rocket flights; the particular configuration for a given flight being determined by the existence of the magnetometer null zones. In one configuration the magnetometer optical axis was placed on the rocket spin axis. The one rocket making use of this configuration was flown on the geographic equator where the inclination of the magnetic field is $30^{\circ}$. With the rocket-spin stabilized so as to maintain a nearvertical orientation throughout its flight, the magnetic field did not intercept the magnetometer null regions and continuous data could be obtained throughout the 
flight. A second configuration involved placement of the magnetometer optical axis at $45^{\circ}$ to the spin axis. A rocket incorporating this magnetometer configuration was flown on the magnetic equator. Here the geomagnetic field is horizontal so that the geomagnetic field vector intercepts a magnetometer null twice each rocket revolution. The third magnetometer configuration used on 6 flights involved the use of two dual-cell magnetometer units with their optical axis placed at approximately $45^{\circ}$ with respect to each other and with each optical axis being inclined $45^{\circ}$ to the rocket spin axis. The outputs of the two dual-cell magnetometers were mixed to form a single continuous output signal, one magnetometer contributing signal when the other was operating in a null region.

The Larmor frequency output of each magnetometer or mixed pair was used to phase-modulate a $231.4-\mathrm{Mc} / \mathrm{s}$ 2-watt telemetry transmitter fed to a 2 or 4 element turnstile antenna placed in the base of the payload. Other payload components included a battery pack consisting of $20 \mathrm{HR} 1$ silver cells to supply power for the magnetometer and transmitter and a switching module containing partially shielded relays for switching operations on the ground. Seven of the payloads carried a Dovap (Doppler) transponder which was used to provide the primary means of trajectory determination. Also, seven of the payloads carried a separate experiment by T. Aggson involving the use of electrometers to measure current between two dipole antennas and the rocket body. The three electrometers were fed into separate voltage-controlled oscillators. The outputs of these oscillators were fed through an amplifier to the telemetry transmitter 
input together with the Rb Larmor frequency. By proper choice and placement of payload components, the magnetic contribution of each payload was $2 \gamma$ or less as measured at the position of the magnetometer sensor in a zero ambient field. Consequently, the magnetic contribution of a payload was small compared with contamination due to the rocket motor, the magnitude of which will be discussed later.

\section{PROCESSING OF DATA}

\section{A. Data Recovery and Preliminary Reduction}

The telemetry signal transmitted from the rocket was modulated by the Larmor frequency output of the magnetometer (roughly 100-150 Kc/s) and the outputs of up to 3 subcarrier oscillators operating at center frequencies of 7,10 and $14 \mathrm{kc} / \mathrm{s}$. At the launch platform the received telemetry signal was recorded on magnetic tape together with a reference frequency, time-code and tape recorder speed-lock reference signal. In the data recovery process a tracking filter was e. ployed to extract the Larmor frequency from the taperecorded signal. A data-flagging procedure was utilized to indicate any failure of the filter to track the desired signal. The output frequency of the tracking filter was used to gate a preset interval over which a $5 \mathrm{Mc} / \mathrm{s}$ reference signal was counted. The accuracy to which the rubidium Larmor frequency can be determined by this procedure is 1 part in $5 \times 10^{6}$ for a counting period of 1 sec. Thus, in principle, if a sample period of $0.1 \mathrm{sec}$ is desired, the Larmor frequency can be measured sufficiently accurately to allow a 0.5 gauss magnetic field to be 
determined with a precision of $0.1 \gamma$. Once the $\mathrm{Rb}^{85}$ Larmor frequency is determined, a value of the scalar magnetic field is found representing the average field over the sampling interval. If the location of the rocket is known at the midpoint of a given sample interval, a reference magnetic field for that location can be computed using the coefficients of a spherical harmonic expansion of the geomagnetic field. The computed reference field $(\mathrm{Bc})$ can be subtracted from the measured field $(\mathrm{Bm})$; the resulting values of $\mathrm{Bm}-\mathrm{Bc}$ form convenient means in which to represent the flight data.

Ideally, the sample intervals used for data reduction should be as short as possible in order to obtain maximum information from each flight. Sample intervals of $10-20 \mathrm{msec}$ have been attempted but the results are erratic; evidently the signal-to-noise ratio of the recorded data is too low to allow accurate counting of the Larmor frequency over such short time spans. Consequently all results presented here are derived by using sample intervals of either 1 sec or an interval corresponding to the roll period of each rocket, typically 150-200 msec. By sampling at the roll periods, errors that are dependent on the angular orientation of the rocket measured in the plane perpendicular to its spin axis are averaged out. The result is a measurement of the scalar magnetic field that is independent of the rocket spin and precise to within a fraction of $1 \%$. This measurement gives the sum of the local geomagnetic field and the spin-axis component of the rocket's magnetic field. The data from most flights exhibit a sinusoidal variation indicating a magnetic contribution along the spin axis of the 
rocket and a precessional motion of the rocket with a period near $30 \mathrm{sec}$. Owing to the smoothness in the variation of the precession period and angle during the upper part of each flight, it is possible to apply a precession correction to the data of the form $C \sin (\omega t+K)$. A computer program was used to apply such corrections to all flights except those evidencing a very minor precessional effect. The values assigned to the constant $\mathrm{C}$ in making these corrections for precession ranged between 1.0 and 4.6 ; these values being chosen to be equal to the observed precessional effect in $\gamma$.

\section{B. Reference Geomagnetic Field}

Assuming that an exact absolute measurement of the ambient magnetic field is made, it is possible to determine the field contribution due to ionospheric currents only when both the position of measurement and the background geomagnetic field as a function of position are exactly known. Spherical harmonic expansions of the geomagnetic field do not give an exact description of the field; the average error on the earth's surface is estimated to be as low as 0.1 to 0.3 per cent (Sugiura and Heppner, 1965). Even this small error can be equal to an appreciable fraction of the ionospheric current contribution or exceed it in some cases. However, the absolute error involved in a particular harmonic expansion is not a serious problem if that expansion can describe precisely the geomagnetic field magnitude at one point on the rocket trajectory relative to any other point. If local anomalies in the geomagnetic field are minor, then the spherical harmonic expansions now available can provide rather precise relative magnetic 
field magnitude within a small region containing the rocket trajectory. Results from a towed proton magnetometer indicate that the region of the rocket flights ủescríned here wàs quite free of appreciabie locaỉ anomaỉies (private communication from $\mathrm{R}$. Hutchinson). Also this region was relatively well-mapped by the Vanguard III satellite, so a good geomagnetic field description is expected from the available expansions. Here the GSFC coefficients prepared by Hendricks and Cain (1966) are used to compute the reference geomagnetic field.

C. Rocket Trajectories

Owing to the ship's motion and other factors, the two shipboard radars were unable to track the rockets over their full trajectories. In one case radar tracking was lost a few seconds into the rocket flight. On several occasions the radars tracked until the rocket was above the atmosphere, and several of the rockets were observed near their impact points by the radars. Independent of the radars, radial velocity data were obtained on 7 of the rocket flights by the Dovap technique (Seddon, 1963). Except on two of these flights, during which the shipboard Dovap transmitter was intentionally shut down near the time of rocket apogee, radial velocity data were obtained essentially throughout the flights.

Given the flight azimuth from fragmentary radar data, it is possible to obtain a trajectory with the Dovap radial velocity data. Even in those cases where the radar data could be extended with ballistic trajectory calculations, the results were clearly quite inaccurate and, therefore, the Dovap data have been relied upon heavily for trajectory information. Mr. J. C. Seddon has contributed much 
to our program by analyzing Dovap data from some flights to arrive at rocket trajectories. Parallel to his efforts we have made use of a procedure given by Jackson (1965) to determine the trajectories. In those cases where only incomplete Dovap data were available, radar data and magnetometer data were used to determine times of peak altitude independent of the Dovap data. On some flights it has been possible to apply several techniques and combinations of techniques to arrive at trajectories in which confidence can be placed; on others uncertainty remains. Further mention of this situation as it pertains to individual flights is contained in Sec. V.

\section{SUPPORTING AND COORDINATED OBSERVATIONS}

With the help of Dr. Alberto Giesecke of the Instituto Geofisico del Peru, it was arranged for the Huancayo Geophysical Observatory to transmit to the Mobile Launch Facility readings of the horizontal (H) component of the magnetic field each half-hour. These readings were used to determine the appropriate launch times for the rocket flights. In addition, magnetic recordings obtained at six temporary recording sites in Peru (see Figure 1) were made available through the courtesy of Dr. A. Giesecke and Dr. S. E. Forbush. As part of their research program on the USNS Croatan, R. Hutchinson and B. Shuman operated a towed proton magnetometer throughout most of the ship's cruise and supplied certain of the results to us. Also, we have been provided with data from ionosonde soundings made by $\mathrm{B}$. Wright from the USNS Croatan near times of the rocket flights. 
Within one hour after several of the magnetometer flights, Blumle, Aikin and Jackson (1965) launched rockets instrumented to measure electron density and electron temperature; here a definite attempt was made to launch the two types of payload as near simultaneously as possible.

V. PRESENTATION OF DATA

\section{A. Flight Data}

In reading the following descriptions of each flight, reference to Figures 1 and 2 will be found useful. The flights are listed chronologically with many of the flight parameters being given in abbreviated form at the first of each flight description. All times and dates are given in Universal Time. The measured magnetic equator referred to in the following flight descriptions was obtained by extending the Peruvian measurements (Private communication from M. Casaverde) out to sea parallel to the magnetic equator calculated from the GSFC coefficients; the calculated equator lies $60-70 \mathrm{~km}$ north of the measured equator.

Flight 14.160: Launch time, 1535 on March 8, 1965; launch coordinates, $0.02^{\circ} \mathrm{N} 84.32^{\circ} \mathrm{W}$; flight azimuth, $277^{\circ}$ (east from true north); adopted peak time, $197.4 \mathrm{sec}$ (from time of launch); adopted peak altitude, $152.67 \mathrm{~km}$; coordinates of peak altitude, $0.01^{\circ} \mathrm{N} 84.93^{\circ} \mathrm{W}(1200 \mathrm{~km}$ north of the measured magnetic equator); average roll period, $161 \mathrm{msec}$. The payload contained a dual-cell magnetometer with its optical axis along the spin (longitudinal) axis of the rocket; this was the only payload not containing electrometers. The adopter 
trajectory was determined by Jackson's (1965) procedure modified to accept an independently-determined peak time. This peak time was determined from the magnetometer minimum reading corrected for horizontal gradient along the flight azimuth. Other methods used for determinations of peak time resulted in values differing from the adopted value by more than $1 \mathrm{sec}$, hence the confidence placed in this trajectory determination is low. The adopted peak-altitude is probably correct to within a few $\mathrm{km}$. See Figure 3.

Flight 14.171: Launch time, 1615 on March 16, 1965; launch coordinates, $12.78^{\circ} \mathrm{S} 78.05^{\circ} \mathrm{W}$; flight azimuth, $295^{\circ}$; adopted peak time, $194.7 \mathrm{sec}$; adopted peak altitude, $149.89 \mathrm{~km}$; coordinates of peak, $12.57^{\circ} \mathrm{S} 78.51^{\circ} \mathrm{W}(18 \mathrm{~km}$ south of the measured magnetic equator); average roll period, $157 \mathrm{msec}$.

The payload contained a 4-cell magnetometer with the configuration described earlier. The modified Jackson procedure was used to determine the trajectory with the peak time being calculated from the magnetometer data itself. In this instance, after making a small correction to take horizontal magnetic gradients into account, the peak time was assumed to correspond to the minimum recorded scalar field value. The flight data are displayed in Figure 4.

Flight 14.172: Launch time, 0604 on March 18, 1965; launch coordinates $12.78^{\circ} \mathrm{S} 77.97^{\circ} \mathrm{W}$; flight azimuth, $276^{\circ}$; adopted peak time, $193.5 \mathrm{sec}$; adopted peak altitude, $149.46 \mathrm{~km}$; coordinates of peak, $12.74^{\circ} \mathrm{S} 78.37^{\circ} \mathrm{W}(5 \mathrm{~km}$ north of measured magnetic equator); average roll period $164 \mathrm{msec}$. 
The payload contained a 4-cell magnetometer. This flight was made near local midnight in an effort to investigate the possible existence of ionospheric current at night. The trajectory was determined in identical manner as for Flight 14.171, described immediately above. See Figure 5 for the flight data. Flight 14.176: Launch time, 1601 on March 18, 1965; launch coordinates, $12.78^{\circ} \mathrm{S}, 78.00^{\circ} \mathrm{W}$; flight azimuth, $269^{\circ}$; adopted peak time, $194.2 \mathrm{sec}$; adopted peak altitude, $151.44 \mathrm{~km}$; coordinates of peak, $12.79^{\circ} \mathrm{S}, 78.48^{\circ} \mathrm{W}$ (on the measured magnetic equator); average roll period, $176 \mathrm{msec}$. The payload contained a 4-cell magnetometer. A trajectory determination by the method employed for Flights 14.171 and 14.172 gave results very similar to that obtained from a Dovap trajectory determined by J.S. Seddon. His trajectory was adopted and it is responsible for the remarkable agreement of the ascent and descent data shown in Figure 6. High confidence is placed in this trajectory; it is probably correct to within a few hundred meters.

Flight 14.174: Launch time, 1624 on March 24, 1965; launch coordinates, $11.73^{\circ} \mathrm{S}, 78.43^{\circ} \mathrm{W}$; flight azimuth $267^{\circ}$; adopted peak time, $200.45 \mathrm{sec}$; adopted peak altitude, $161.38 \mathrm{~km}$; coordinates of peak, $11.74^{\circ} \mathrm{S}, 78.82^{\circ} \mathrm{W}(100 \mathrm{~km}$ north of the measured magnetic equator); average roll period $176 \mathrm{msec}$.

The payload contained a 4-cell magnetometer; the adopted trajectory was determined as for Flights 14.171 and 14.172. See Figure 7.

Flight 14.173: Launch time, 1541 on March 26, 1965; launch coordinates, $10.17^{\circ} \mathrm{S}, 79.50^{\circ} \mathrm{W}$; flight azimuth $266^{\circ}$; adopted peak time, $197.4 \mathrm{sec}$; adopted 
peak altitude $155.51 \mathrm{~km}$; coordinates of peak, $10.19^{\circ} \mathrm{S}, 79.93^{\circ} \mathrm{W}(240 \mathrm{~km}$ north of the measured magnetic equator); average roll period, $142 \mathrm{msec}$.

The payload contained a 4-cell magnetometer. Due to suspected radiofrequency interference the shipboard Dovap transmitter was shut off near the time of rocket peak altitude; hence only partial trajectory data were obtained. Partial Dovap and radar data were used to determine peak time, flight azimuth and the coordinates of the position of peak altitude. Then an artificial trajectory was generated wherein it was assumed that the entire path of the rocket was on the vertical line through apogee. A reference magnetic field was determined for this trajectory and corrected for the horizontal magnetic field gradient encountered in the actual flight path of the rocket. Due to the use of this procedure the $\mathrm{Bm}-\mathrm{Bc}$ data values are less certain than those from other flights, the uncertainty arising through the computation of Bc. See Figure 8.

Flight 14.175: Launch time, 1608 on March 27, 1965; launch coordinates, $14.17^{\circ} \mathrm{S}, 77.95^{\circ} \mathrm{W}$; flight azimuth, $293^{\circ}$; adopted peak time, $197.15 \mathrm{sec}$; adopted peak altitude, $151.93 \mathrm{~km}$; coordinates of peak, $13.99^{\circ} \mathrm{S}, 78.39^{\circ} \mathrm{W}(130 \mathrm{~km}$ south of the measured magnetic equator); average roll period, $147 \mathrm{msec}$.

The payload contained a 4-cell magnetometer. As in the case of Flight 14.173, only partial Dovap data were obtained and the same procedure was used for determining an artificial one-dimensional trajectory, corrected for horizontal gradient effect. The reduced data are shown in Figure 9.

Flight 14.70: Launch time, 1547 on March 29, 1965; launch coordinates, $12.08^{\circ} \mathrm{S}, 78.23^{\circ} \mathrm{W}$; flight azimuth, $244^{\circ}$; adopted peak time, $214.3 \mathrm{sec}$; adopted peak altitude, $181.46 \mathrm{~km}$; coordinates of peak, $12.32^{\circ} \mathrm{S}, 78.72^{\circ} \mathrm{W}(40 \mathrm{~km}$ north of the measured magnetic equator); average roll period, $136 \mathrm{msec}$. 
This payload contained a dual-cell magnetometer with its optical axis aligned $45^{\circ}$ to the rocket spin axis. The rocket achieved high altitude because of its low

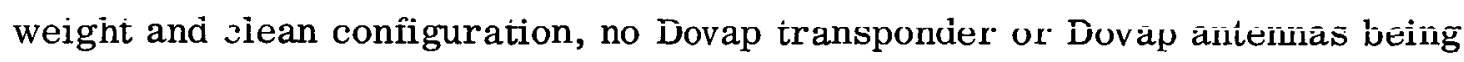
aboard. Unfortunately, only fragmentary radar tracking was obtained. However, the flight azimuth was almost exactly along the direction of zero horizontal gradient in the geomagnetic field, a factor which contributed to a fairly accurate determination of peak time by two methods. One involved a determination from the magnetometer minimum reading; the second determination was made by assuming that the flight magnetometer intercepted the lower-altitude boundary of the ionospheric current sheet at the same altitude on ascending and descending portions of the flight. The adopted peak time was that obtained by the latter method. As in the case of Flights 14.173 and 14.175 , an artificial one-dimensional trajectory was generated. A value of peak altitude was calculated for this flight on the basis of ascending flight time corrected for the predicted effect of atmospheric drag. Consequently, the adopted peak altitude may be in error by several kilometers. The flight data are shown in Figure 10.

B. Ground Magnetic Data

The Kp values on the days of each flight are given on Figure 2. There it is seen that, except for March 24, 26 and 27, magnetic activity was low. In no case did Kp exceed $2_{0}$ during the 3 -hour interval containing any flight. Sudden commencement magnetic storms occurring on March 2 and 22 were reported at certain high-latitude observatories and at several low-latitude observatories. These two storms evidently were not reported as such by some stations, for example, Fredericksburg and Honolulu. 
As part of a more extensive analysis by one of us (K. B.) scalings have been made of magnetic records obtained at the Peruvian observing stations indicated on Figure 1. Daily ranges of the horizontal component $\mathrm{R}(\mathrm{H})$ have been determined by a semi-automatic procedure which determines the daily maximum of the smoothed $\mathrm{H}$ trace and subtracts from it an appropriate point on a least squares straight line fit to scalings at $21,23,01$ and 03 hours on the proximate nights' $H$ trace. The resulting mean values of $R(H)$ for the period March 1-23, 1965 are indicated on Figure 11A; early closure of several of the temporary observatories in the third week of March dictated the end-point of this period. The curve drawn on Figure 11A represents the average $R(H)$ as a function of distance from the magnetic equator for the March period.

Values of $\Delta H, \Delta D$ and $\Delta \mathrm{Z}$ have been obtained at each of the operating Peruvian observatories for the time of each rocket flight. Such values were obtained by subtracting a nighttime level (established as for the $\mathrm{R}(\mathrm{H})$ determination described above) from the appropriate trace value at the time of each flight. The resulting $\Delta H$ values also are plotted on Figure 11A. On Figure $11 \mathrm{~B}$ these $\Delta \mathbf{H}$ values are replotted after being multiplied by a normalization factor $\mathrm{N}_{\tau}=$ $100 \gamma / \Delta \mathrm{H} \tau$ (Huancayo) where $\tau$ represents the time of a particular rocket flight. Later we wish to relate the flight data to a "standard electrojet" defined so that it produces $\triangle H=100 \gamma$ at Huancayo and has a particular current configuration regardless of which day it appears above Huancayo. The normalized values plotted on Figure 11B help to determine if this is an acceptable procedure since they indicate the day-to-day latitude variability in the electrojet on the days of interest. 


\section{INTERPRETATION AND DISCUSSION OF DATA}

\section{A. Current Density Profiles}

A primary goal of this study is to obtain an experimentally-determined current cross-section of the equatorial electrojet. Once the experimental crosssection is established to within the limit allowed by the accuracy of the rocket and ground magnetic data, the profile can be compared to a computed profile such as that of Sugiura and Cain (1966).

At middle latitudes, where the local magnetic field of the ionospheric current approximates that of an infinite current sheet, the change of $\mathrm{Bm}-\mathrm{Bc}$ with altitude is directly proportional to the ionospheric current density. The infinite current sheet approximation is less applicable to the equatorial electrojet in view of the finite width of that current. This point is illustrated by an altitude profile of the magnetic field within the equatorial electrojet calculated by Sugiura and Cain on the basis of their theoretical conductivity profile (ignoring induction effects). In the infinite current sheet case the altitude versus $\mathrm{Bm}-\mathrm{Bc}$ plot trends vertically outside the region of the current sheet; for the equatorial electrojet this is not so. A simplified calculation has been made of the error introduced into current density profiles by the assumption of an infinite current sheet. For this calculation the flight data have been used to determine the approximate integrated ionospheric current as a function of distance from the magnetic equator. Both the ionospheric and an assumed (25\% of the ionospheric current) induced current were considered. The result indicates that the infinitesheet approximation yields an error of $7 \%$ or less in the calculated value of current density at any point. Within the current region the error discussed here is 
not serious and so we proceed to obtain current density profiles using the infinite sheet approximation.

Since the accuracy of determining the current density depends directly upon the shape of the altitude versus $\mathrm{Bm}-\mathrm{Bc}$ plot, any error in that shape is quite serious. Data plots using various calculated trajectories for a particular flight indicate that an error in the determination of trajectory peak altitude, while definitely creating an error in the altitude location of the current sheet, does not contribute as significantly to changing the shape of the altitude versus Bm-Bc plot. On the other hand, error in the calculated peak time or failure to correct exactly for horizontal gradients in the reference magnetic field will markedly alter the shape of the altitude versus $\mathrm{Bm}-\mathrm{Bc}$ plot. Figure 12 illustrates the dependence of the plot shape upon the choice of peak time. Despite the dependence, we find empirically that the mean altitude versus $\mathrm{Bm}-\mathrm{Bc}$ plot, obtained by averaging the ascent and descent legs of a flight, is substantially independent of the adopted peak time. Therefore, instead of treating the ascent and descent data sets independently, one can combine them by averaging; to a large extent this procedure will eliminate two nearly indistinguishable sources of error, incorrect choice of peak time and incorrect horizontal magnetic gradient corrections. The current density profiles presented in Figure 13 are obtained by setting $J=10 / 4 \pi\left(\Delta B_{h_{1}}-\Delta B_{h_{2}}\right) /\left(h_{2}-h_{1}\right)$ amp $/ \mathrm{km}^{2}$ where $\Delta B$ in $\gamma$ is obtained from the average of ascent and descent data for each flight, $h$ being altitude in $\mathrm{km}$. Those current density profiles in Figure 13 derived from the several flights near the center of the electrojet indicate that the lower boundary of the electrojet is very near $90 \mathrm{~km}$. The maximum current density is found to be near altitude $108 \mathrm{~km}$ proximate to the magnetic equator. Above the altitude of maximum 
current density, the current density appears to decrease monotonically with altitude until it is near zero at altitude $140 \mathrm{~km}$.

Flights $14.174,14.175,14.17 \overline{3}$ and 14.160 are successively farther from the center of the electrojet. Except for Flight 14.160, the current density profiles obtained from these flights are roughly similar to those found for the nearly onequator flights although the height-integrated current density clearly decreases with distance from the magnetic equator. Flight 14.160, on the geographic equator, results in a current density profile extending from near $100 \mathrm{~km}$ to 140 $\mathrm{km}$ altitude and having a broad maximum centered near $116 \mathrm{~km}$ altitude. B. Normalization of Data

The equatorial electrojet amplitude varied from one day to the next on the days of the rocket flights (see Figure 11) and the rocket flights occurred at different times relative to the times of electrojet daily maximum (see Figure 2). Therefore, it is necessary to normalize the flight data by use of the groundbased magnetic observations in order to arrive at a complete profile of the electrojet.

On the basis of the ground data presented in Figure 11B the assumption is made that the position and configuration of the electrojet is the same during each flight. The rocket flights reported here took place approximately $2^{\circ}$ longitude west of the ground observatories. In the absence of disturbance magnetic activity the electrojet amplitude at the flight longitude should lag that at the Peruvian observatories by about 8 minutes in time. This statement presupposes that the electrojet is local-time dependent. A minor correction is included in the normalization to account for this longitude factor. Huancayo is the most reliable equatorial observatory used, hence the flight data are normalized 
according to the Huancayo observations. The various factors applied to normalize each data set to a standard electrojet producing $\Delta \mathrm{H}=100 \gamma$ at Huancayo are given in Table I.

On Figure 13 the actual current density is designated by $\mathrm{J}$, and $\mathrm{J}$ ' denotes the normalized current density determined according to the corrections indicated in Table I. The similarly normalized changes in total field due to passage through the current sheet for each flight are indicated on Figure 11B. Note that data from the single nighttime flight, Flight 14.172, are not included here.

Two flights reported by Maynard and Cahill (1965), UNH 65-2 and UNH 65-5, are included in Table $I$ and Flight UNH $65-5$ also is indicated on Figure 11B. In addition, we have determined current density profiles from the published data according to the method outlined above (See Figure 13).

The current density profile obtained from Flight 14.176 deserves special mention. The trajectory obtained by J. C. Seddon for that flight appears to be sufficiently accurate to allow derivation of current density profiles from both the ascent and descent portions of the flight. These two profiles are indistinguishable above altitude $133 \mathrm{~km}$; below they agree rather closely.

Table I. Factors entering into normalization of flight data to an electrojet producing $\triangle H=100 \gamma$ at Huancayo. The Huancayo $\triangle \mathrm{H}$ values are for the midtimes of each flight. Row 5 gives the correction in $\gamma$ to account for the difference in longitude between Huancayo and the location of each flight. The ratio $\mathrm{J} ' / \mathrm{J}$ is the normalization factor relating the normalized and actual current densities. Flights UNH 65-2 and UNH 65-5 are those reported by Maynard and Cahill (1965a). 
TABLE I

Time Lag, Time Lag

\begin{tabular}{|c|c|c|c|c|c|}
\hline Flight & Date & Huancayo $\triangle H$ & Minutes & Correction, $y$ & $J^{\prime} / J$ \\
\hline 14.160 & March 8 & 100.6 & 37 & -15 & 1.17 \\
\hline UNH $65-2$ & 9 & 107 & 36 & -15 & 1.09 \\
\hline UNH $65-5$ & 12 & 100 & 24 & -7 & 1.08 \\
\hline 14.171 & 16 & 120.6 & 12 & +3 & 0.809 \\
\hline 14.172 & 18 & (Nighttime Fli & & & \\
\hline 14.176 & 18 & 117.4 & 12 & 0 & 0.852 \\
\hline 14.174 & 24 & 107.0 & 14 & +5 & 0.893 \\
\hline 14.173 & 26 & 88.8 & 18 & -3 & 1.16 \\
\hline 14.175 & 27 & 65.1 & 12 & dist. & 1.54 \\
\hline 14.70 & 29 & 101.5 & 13 & +5 & 0.939 \\
\hline
\end{tabular}

C. Cross-sectional Profile and a New Model for the Electrojet

Values of current density, obtained from scaling of hand-drawn, smoothed curves through the data displayed in-Figure 13, have been used to compile Figure 14, an experimentally determined cross-section of the equatorial electrojet. The contours depicted on Figure 14 were uniquely determined by a procedure involving linear interpolation in the horizontal direction only. Thus, any error in the location of the current density contours directly reflects error in the individual profiles of Figure 13 or error introduced by a hand-smoothing of those profiles. The construction of Figure 14 is based upon the assumption that the day-to-day variation in the electrojet is in intensity only and not in location or configuration. The values assigned to the contours of current density refer to an electrojet producing $\Delta \mathrm{H}=100 \mathrm{y}$ at Huancayo. 
Several features of Figure 14 may be due to inaccuracies inherent in the flight data or to simplifying assumptions made in the reduction of the data to obtain current density profiles. In particular, the effects of induced currents have been ignored in the reduction and the finite width of the electrojet was not taken into account in determining the individual current density profiles. The effect of ignoring the induced current of finite but unknown extent is that the current density obtained at the higher altitudes is slightly higher than it should be. This very minor measurement error occurs due to the negative gradient (with height) of the field from induced currents; within the main part of the electrojet, the error is negligible, and below the electrojet the effect is small compared to the effect of the finite width of the electrojet. The finite width of the eastward electrojet in itself produces a small deviation of the altitude versus $\mathrm{Bm}-\mathrm{Bc}$ plots below the electrojet. As shown by Sugiura and Cain (1966), the effect is the same as that of a weak westward current just below the main eastward current. This apparent westward current, seen on several of the profiles in Figure 13, has been ignored in the compilation of Figure 14.

Of particular interest on Figure 14 is the behavior of the cross-sectional profile in the immediate vicinity of the magnetic equator. The asymmetry there, the thinness of the current relative to that just to the north and south, and the observed latitudinal extent of the electrojet are unexpected on the basis of the model electrojet computed by Sugiura and Cain. Their calculation gives values of the effective conductivity

$$
\sigma_{\text {yy }}=\sigma_{1}+\sigma_{2}^{2} /\left(\sigma_{0} \tan ^{2} I+\sigma_{1}\right)
$$


where $\sigma_{0}, \sigma_{1}$ and $\sigma_{2}$ are the direct, Pederson and Hall conductivities, respectively, and $I$ is the inclination.

If it is assumed that the vertical current through the region of the electrojet is entirely inhibited by polarization of the layer, then the horizontal currents are

$$
\begin{aligned}
& \mathbf{J}_{\mathbf{x}}=\sigma_{\mathbf{x} x} \mathbf{E}_{\mathbf{x}}+\sigma_{\mathrm{xy}} \mathbf{E}_{\mathbf{y}} \\
& \mathrm{J}_{\mathbf{y}}=-\sigma_{\mathrm{xy}} \mathbf{E}_{\mathbf{x}}+\sigma_{\mathrm{yy}} \mathbf{E}_{\mathbf{y}}
\end{aligned}
$$

where $\mathrm{x}$ and $\mathrm{y}$ are positive southward and eastward, respectively (Price, 1965). Exactly on the equator $\sigma_{\mathrm{xy}}=0$; if it is assumed that $\mathrm{E}=\mathrm{E}_{\mathrm{y}}$, then the horizontal current is eastward and is given by $J_{y}=\sigma_{y y} E_{y}$. However, Maeda (1965) has shown that $\sigma_{\mathbf{x y}}$ is non-zero just off the equator and reaches a maximum exceeding $\sigma_{\mathrm{yy}}$ at about $56 \mathrm{~km}$ from the equator. Since the electrojet is limited in latitudinal extent, we expect north-south currents to be inhibited. Assuming complete inhibition of the north-south current requires, from Equation 2,

$$
E_{x}=-\frac{\sigma_{x y}}{\sigma_{x x}} E_{y}
$$

The expressions for $\sigma_{\mathbf{x y}}$ and $\sigma_{\mathbf{x}}$ are given by Chapman (1956):

$$
\begin{aligned}
& \sigma_{x x}=\sigma_{0} \sigma_{1}\left(\sigma_{0} \sin ^{2} I+\sigma_{1} \cos ^{2} I\right) \\
& \sigma_{x y}=\sigma_{0} \sigma_{2} \sin I\left(\sigma_{0} \sin ^{2} I+\sigma_{1} \cos ^{2} I\right)
\end{aligned}
$$

Hence

$$
\mathbf{E}_{\mathbf{x}}=\frac{\sigma_{2}}{\sigma_{1}} \sin \mathrm{I} \mathrm{E}_{\mathbf{y}}
$$


South of the equator $\sin I$ is negative, it is zero at the equator and positive to the north. Thus two regions of polarization field $E_{x}$ occur: the one south of the equator is directed northward and the one to the north of the equator is directed southward. Substituting Equation (7) into Equation (3) yields

$$
J_{y}=\left(\frac{\sigma_{2}}{\sigma_{1}} \cdot \sigma_{x y} \sin I+\sigma_{y y}\right) E_{y}
$$

This expression for $J_{y}$ constitutes a model for the equatorial electrojet. Since sin I has opposite sign on either side of the equator, this model yields an asymmetrical electrojet. The model gives the same configuration exactly on the equator as the model of Sugiura and Cain but the current density is decreased to the south of the equator and enhanced on the north side relative to the Sugiura and Cain model. The difference between this model and that of Sugiura and Cain will be greatest a few tens of kilometers to the north and south of the magnetic equator where Maeda's calculations show $\sigma_{\mathbf{x y}}$ to be maximum. The ratio $\sigma_{2} / \sigma_{1}$ is altitude-dependent, it being greatest near altitude $100 \mathrm{~km}$. This ratio at $100 \mathrm{~km}$ is 27 according to a table of numerical values given by Chapman (1956). Maeda's calculation of $\sigma_{y y}$ shows that the ratio of $\sigma_{x y} / \sigma_{y y}$ is approximately $1 / 2$ at altitude $100 \mathrm{~km}$ and where $I=1^{\circ}$. At this value of $I$ the term in Equation (8) containing the layer conductivity $\sigma_{\mathbf{x y}}$ clearly is important in determining the current density if the southward current is completely inhibited as assumed for this model.

The asymmetry shown in Figure 14 may not be entirely explained by the model described above. Another factor of possible importance is the modification to the inclination of the magnetic field caused by the electrojet. The electrojet acts to decrease the inclination of the field to the north of the equator and to 
increase it to the south. This modification tends to shift northward the regions where the effective layer conductivity $\left(\sigma_{2} / \sigma_{1}\right) \sigma_{x y} \sin I$ is important. A complete calculation taking intó account the observed electrojet configuration is required to determine the magnitude of this effect, however, the near-equatorial portion of Figure 14 strongly suggests it's importance.

D. Fine Structure in the Electrojet

Due to the smoothing applied to the profiles of Figure 13, the contours on Figure 14 do not show any indication of fine structure in the electrojet. Most of the profiles in Figure 13 do indicate the existence of 2 or more close-spaced maximums near the altitude of peak current density. This variation may be due to errors caused by precessional effects, particularly in the case of Flights 14.173 and 14.70 to which no precession corrections were applied. The data from these two flights evidenced little precessional effect; hence, no correction was made during the data reduction process. Yet the scatter in the upper portions of the current density profiles obtained from these 2 flights (Figure 13) indicates that a precessional correction should have been applied. Likewise, comparison of the scatter in the profiles of these 2 flights with that in the profiles of all other flights, to which a correction was applied, attests to the success of the precessional corrections which were used. Nevertheless, close examination of the flight data obtained with high sampling rates is suggestive that much of the apparent structure in the profiles of Figure 13 is due merely to spin and precession modulation.

E. The Nighttime Electrojet

One rocket, Flight 14.172 was launched near local midnight. The resulting altitude versus $\mathrm{Bm}-\mathrm{Bc}$ plots contained in Figure 5 trend almost vertically except 
for noticeable modulation due to precession of the rocket. A slight offset appears in the uncorrected data near altitude $100 \mathrm{~km}$. Straight lines fitted by the least squares method to the altitude versus $\mathrm{Bm}-\mathrm{Bc}$ plots in the altitude ranges 60 to 90 and 110 to $150 \mathrm{~km}$, respectively, when extended to the $100 \mathrm{~km}$ level (dashed portions on Figure 5), indicate an electric current near that altitude. A single precession correction of the form $C \sin (\omega t+k)$ did not satisfactorily remove the precession modulation from the data; a correction corresponding to a precession period of $36 \mathrm{sec}$ largely removes the precession modulation from the ascent data (plot I on Figure 5), whereas one corresponding to a precession period of 35 sec is most effective when applied to the descent data (plot II on Figure 5). Clearly, the offset of the least squares-fitted lines at the $100 \mathrm{~km}$ level depends little on precession modulation. Hence, we can safely conclude that a small nighttime electrojet did exist at the time of the flight. The current was westward, opposite to the daytime electrojet, and gave rise to a discontinuity with magnitude near $6 \gamma$. Note also that indications of a westward nighttime electrojet have been found by Balsley (1965).

F. Currents Induced in the Earth

The data presented in Figure 11B provide a means of estimating what proportion of the observed diurnal magnetic field variations is due to the primary ionospheric currents and what is the result of secondary currents induced in the ground.

The points on the upper curve of Figure 11B show the total change in Bm-Bc as the rockets passed through the jet. These readings are therefore determined mainly by the intensity of the ionospheric currents and, on the assumption that the vertical thickness of the jet is small compared with its height, they are 
substantially unaffected by the induced earth currents. On the other hand, the ground data (lower curve of Figure 11B), are influenced by both primary (ionospheric) currents and secondary (ground) currchts. Neglecting the smali phase difference between the two current systems it is, therefore, a simple matter to differentiate between the two field components. On this basis the value of $\Delta \mathrm{H}$ (induced) $/ \triangle \mathrm{H}$ (external) obtained at various distances from the magnetic equator $(150 \mathrm{~km} \mathrm{~S}$ to $250 \mathrm{~km} \mathrm{~N})$ ranges from 0.23 to 0.33 ; the average of 8 such determinations was 0.28 .

\section{SUMMARY}

The results of 8 rocket flights into and near the equatorial electrojet just off the coast of Peru are presented here. One nighttime flight on the magnetic equator detected a slight westward current near an altitude of $100 \mathrm{~km}$. A noontime flight on the geographic equator penetrated a current layer with maximum current density near altitude $115 \mathrm{~km}$. This layer evidently is due primarily to the Pederson current $\sigma_{1} \mathbf{E}_{\mathbf{y}}$ and is the same one responsible for the mid-latitude Sq magnetic variations. The 6 other rockets were flown within $200 \mathrm{~km}$ of the measured magnetic equator where they penetrated the equatorial electrojet. This current, due to the sum of the Pederson current and Hall currents enhanced by polarization electric fields, has a lower boundary near $87 \mathrm{~km}$ altitude and maximum current density of $10 \mathrm{amp} / \mathrm{km}^{2}$ near $107 \mathrm{~km}$ altitude. According to our measurements, the electrojet appears to have a lower maximum current density and is more extended in latitude than is indicated by the model calculation of Sugiura and Cain (1965). Also, the cross-sectional current density profile is more complex proximate to the equator than can be accounted for by the Sugiura and Cain model. 
The complexity in the profile suggest the importance of north and south polarization fields just off-equator. A model based on the assumption of complete inhibition of the north-south current leads to derivation of an 'effective' conductivity involving the layer conductivities $\sigma_{\mathbf{x y}}$ and $\sigma_{\mathrm{yy}}$. This model appears to account qualitatively for some features of the observed complexity of the electrojet.

A detailed comparison of the rocket data with the appropriate ground data allowed a determination of the induced part of the daily magnetic variations in H. On the basis of some simplifying assumptions it was found that the ratio of induced to inducing field was 0.28 . 


\section{REFERENCES}

Anderson, E. R., Single-depth charts of the World's ocean basins at depths to 3500 fãthoms, Naval Eiectronics Lab., Rept. 1252, San Diego, Calif., 1964.

Balsley, B. B., Evidence for a nighttime westward current in the equatorial E-Region, Report on Equatorial Aeronomy, Proceedings of the Second International Symposium on Equatorial Aeronomy, F. de Mendonça, Ed., Brazilian Space Commission, São Paulo, 300-301, 1965.

Bartels, J., and H. F. Johnston, Geomagnetic tides in horizontal intensity at Huancayo, Terrest. Magnetism and Atmospheric Elec., 45, 269-308, 1940.

Bloom, A. L., Principles of operation of the rubidium vapor magnetometer, Applied Optics, 1, 61-68, 1962.

Blumle, L. J., A. C. Aikin and J. E. Jackson, Rocket observations of the equatorial ionosphere, Report on.Equatorial Aeronomy, Proceedings of the Second International Symposium on Equatorial Aeronomy, F. de Mendonça, Ed., Brazilian Space Commission, São Paulo, 86-87, 1965.

Cahill, L. J., Jr., Investigation of the equatorial electrojet by rocket magnetometer, J. Geophys. Res., 64, 489-503, 1959.

Chapman, S., The electrical conductivity of the ionosphere, a review, Supplemento Nuovo Cimento, $\underline{4}, 1385-1412,1956$.

Forbush, S. E., and M. Casaverde, Equatorial electrojet in Peru, Carnegie Institution of Washington Publication 620, 135 pp., 1961. 
Hendricks, S. J., and J. C. Cain, Magnetic field data for trapped-particle evaluations, J. Geophys. Res., 71, 346-347, 1966.

Jackson, J. E., Determination of rocket trajectories from minimal CW tracking data, NASA Rept. X-615-65-281, Goddard Space Flight Center, Greenbelt, Md., 42 pp., 1965.

Maeda, K. I., Conductivity structure of the equatorial ionosphere, Report on Equatorial Aeronomy, Proceedings of the Second International Symposium on Equatorial Aeronomy, F. de Mendonça, Ed., Brazilian Space Commission, São Paulo, 419-423, 1965.

Maynard, N. C., and L. J. Cahill, Jr., Preliminary results of measurements of Sq currents and the equatorial electrojet near Peru, J. Geophys. Res., 70, 5975-5977, $1965 a$.

Maynard, N. C., and L. J. Cahill, Jr., Measurement of the equatorial electrojet over India, J. Geophys. Res., 70, 5923-5936, $1965 \mathrm{~b}$.

Onwumechilli, C. A., A study of the equatorial electrojet, I, II, J. Atmospheric and Terrest. Phys., 13, 222-257, 1959.

Price, A. T., The effective conductivity of the equatorial ionosphere for the Sq current system, Report on Equatorial Aeronomy, Proceedings of the Second International Symposium on Equatorial Aeronomy, F. de Mendonça, Ed., Brazilian Space Commission, São Paulo, 415-418, 1965.

Rao, K. N., and K. S. Raja Rao, Quiet day magnetic variations near the magnetic equator, Nature, 200, 460-461, 1963. 
Seddon, J. C., Preliminary report on the single station Doppler-interferometer rocket tracking technique, NASA TN D-1344, NASA, Washington, 30 pp., 1963.

Singer, S. F., E. Maple and W. A. Bowen, Jr., Evidence of ionospheric current from rocket experiments near the geomagnetic equator, J. Geophys. Res., 56, 265-281, 1951 .

Sugiura, M., and J. C. Cain, A model equatorial electrojet, J. Geophys. Res., 71, $1869-1878,1966$.

Sugiura, M. and J. P. Heppner, The Earth's magnetic field, in Introduction to Space Science, W. N. Hess, Ed., Gordon and Breach, New York, 919 pp., 1965. 


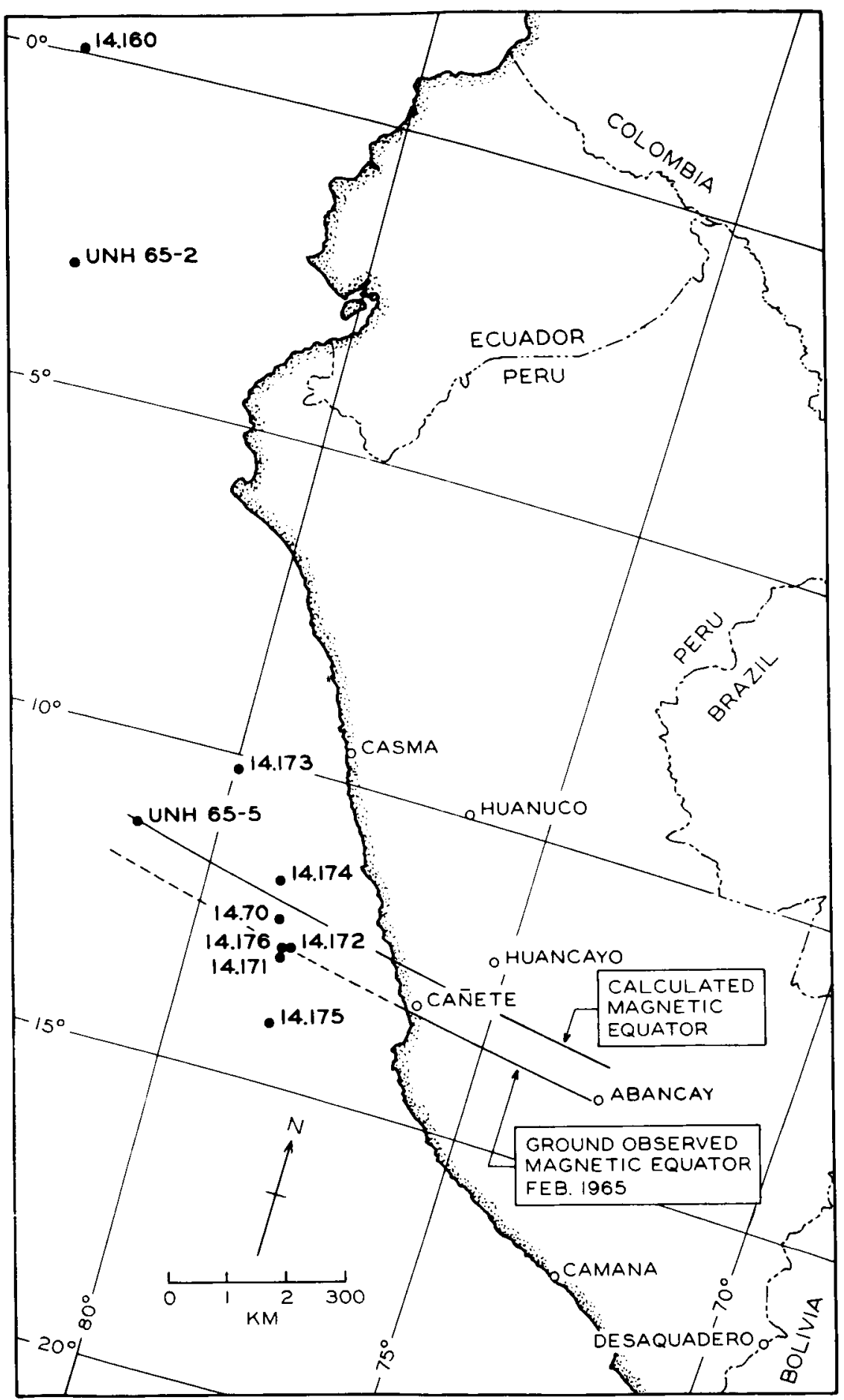

Figure 1-Locations of the midpoints of the 8 rocket flights and also flights UNH 65-2 and UNH 65-5 launched by Maynard and Cahill (1965a). Also shown are the locations of 7 temporary or permanent magnetic observatories from which data were utilized. Latitudes and longitudes are south and west, respectively. 


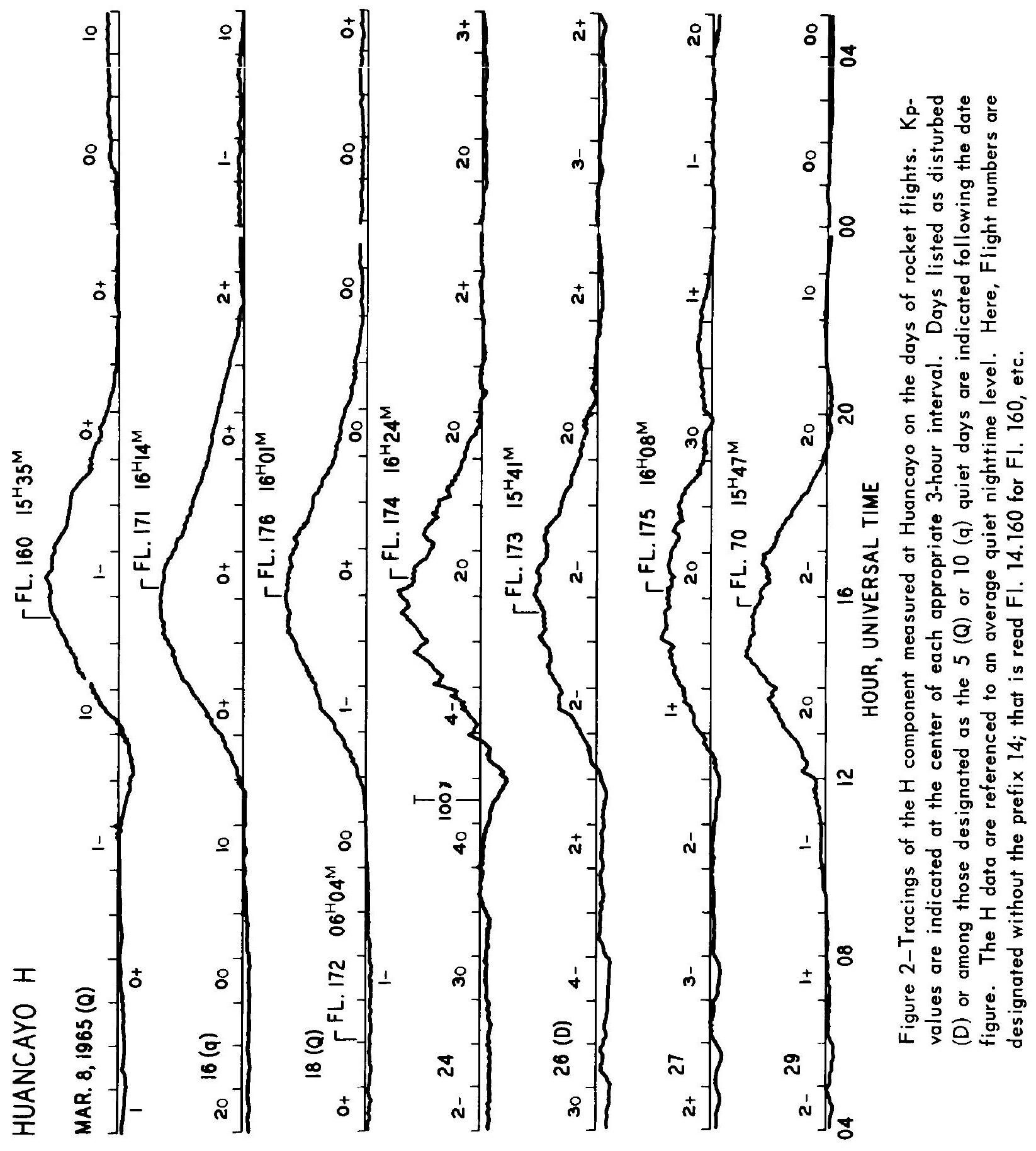




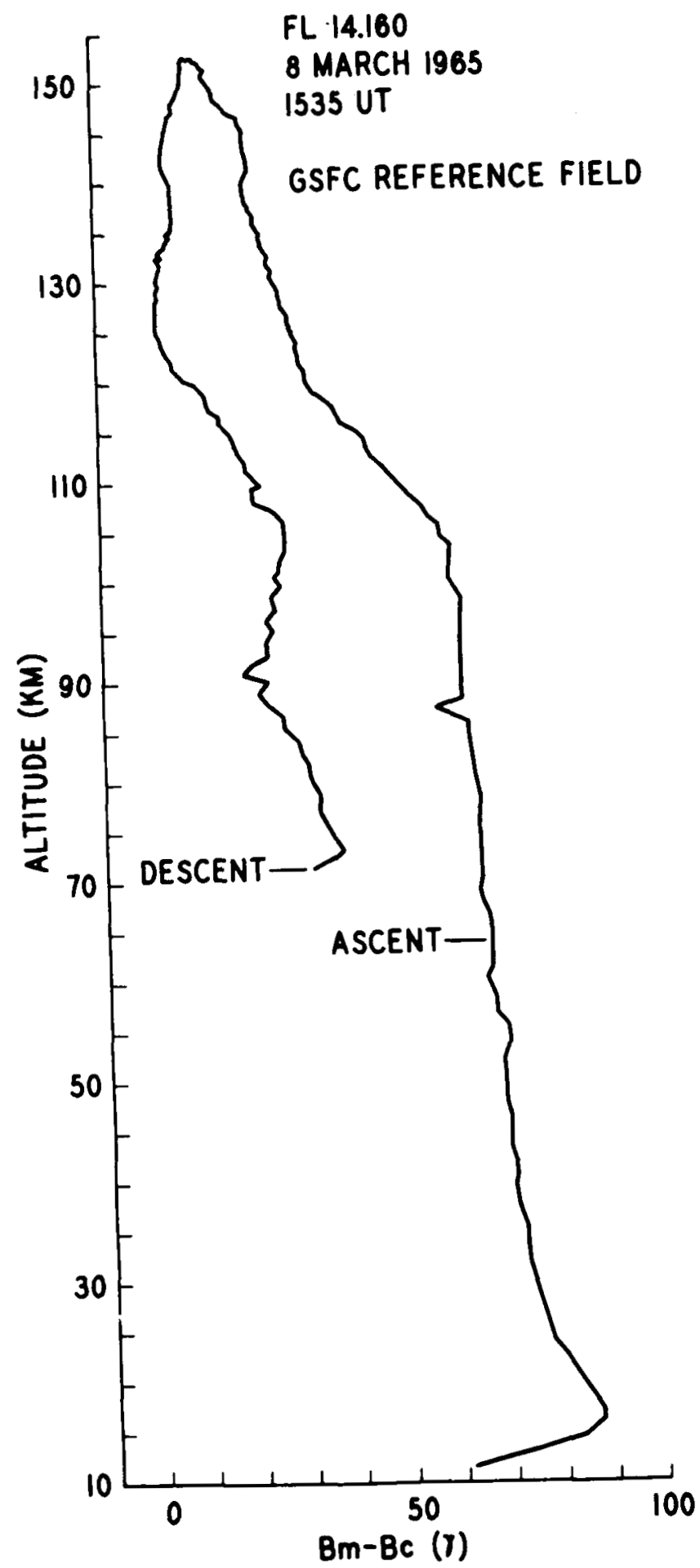

Figure 3-Data from Flight 14.160 plotted in the form of altitude versus the measured scalar field Bc. The plot is formed by a straight-line connection of all data points obtained with a 1 sec sample interval. Although ascent data taken below $60 \mathrm{~km}$ altitude is shown on this and following diagrams, tho se data are not reliable due to possible trajectory errors. Descent data below an altitude of approximately $80 \mathrm{~km}$ are seriously affected by the magnetic field of the rocket as it turns over on re-entry. 


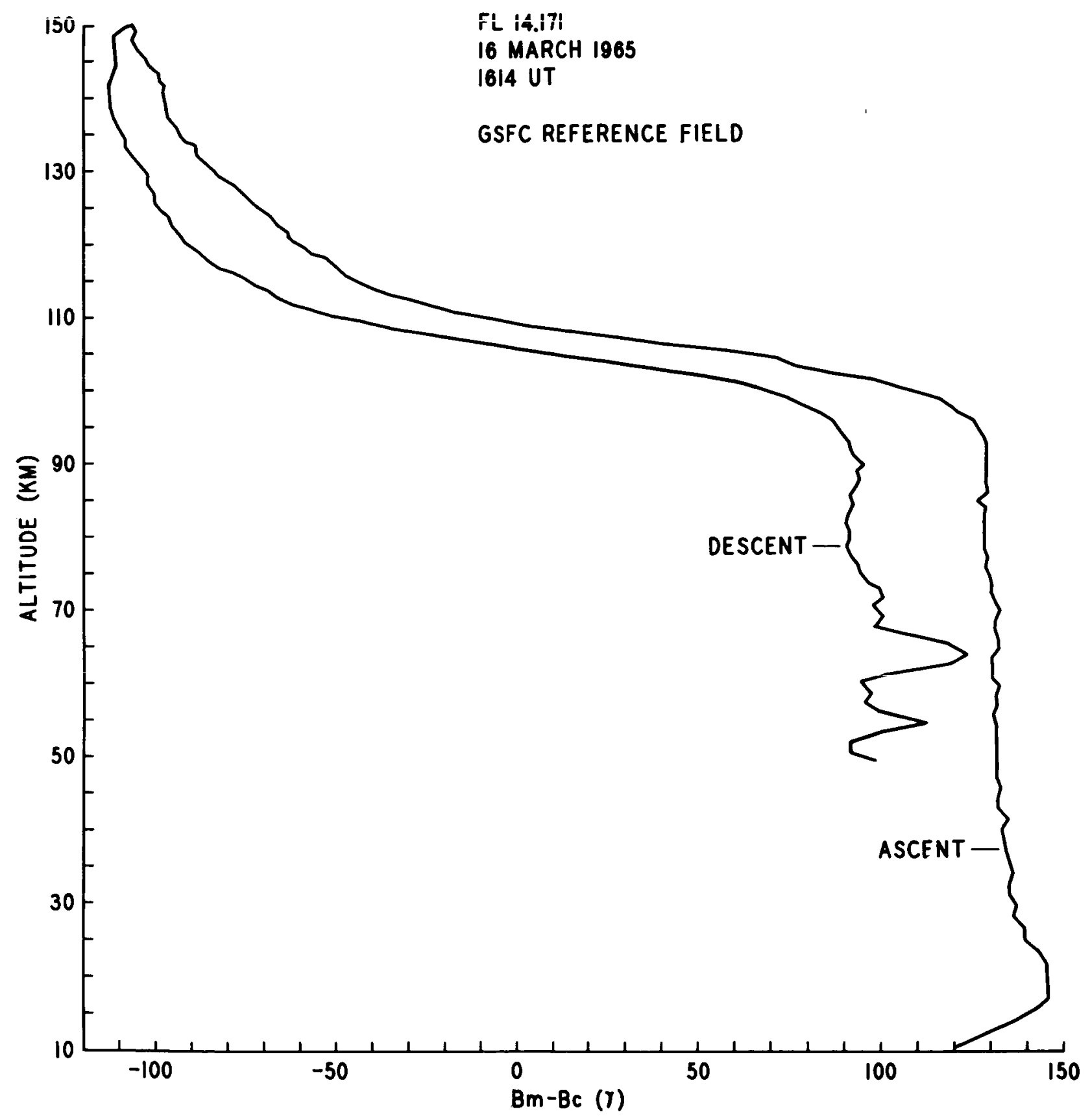

Figure 4-Data from Flight 14.171; see the title for Figure 3. 
FL. 14.172

18 MAR 1965

0604 UT

GSFC REFERENCE FIELD

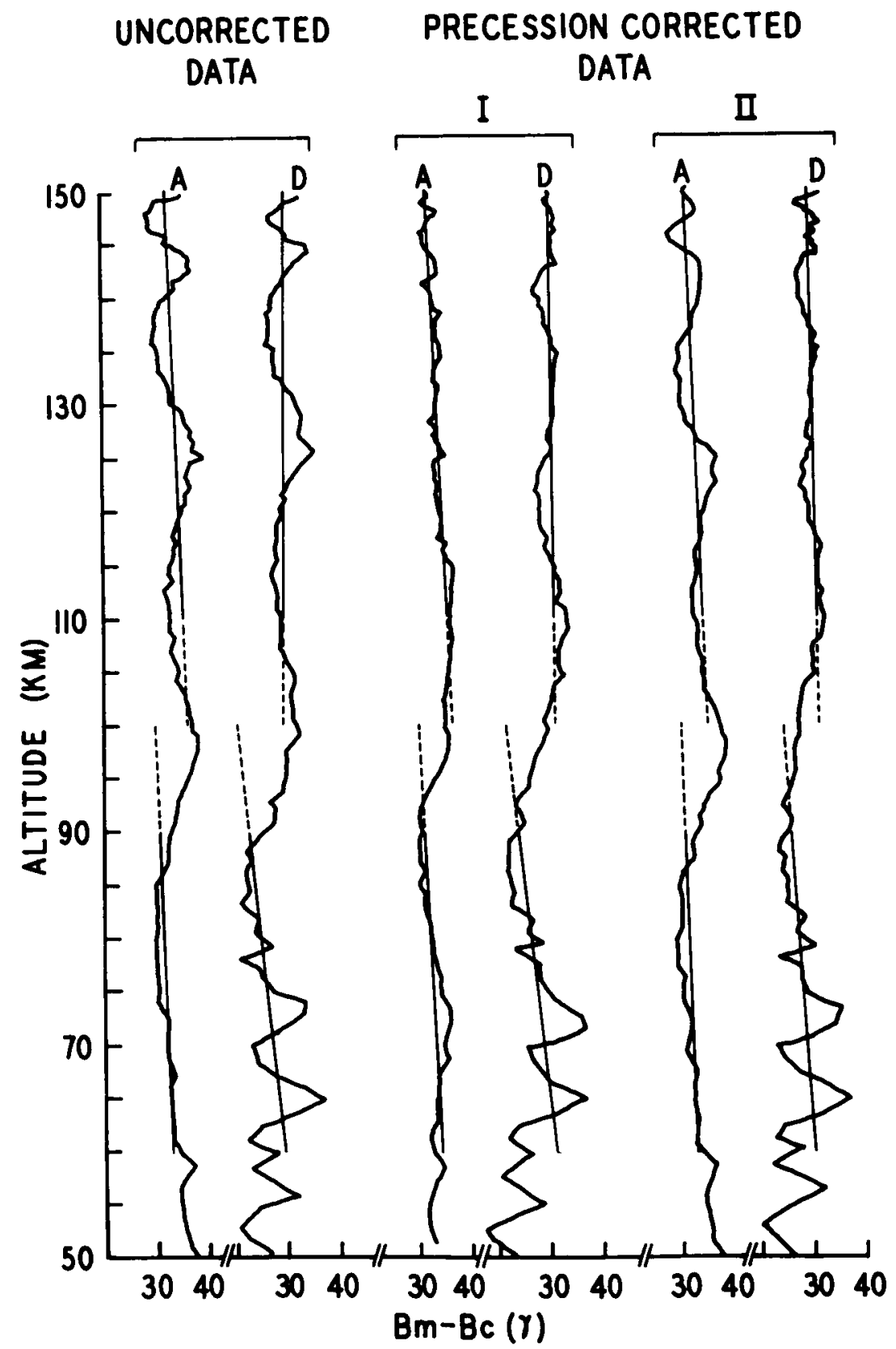

Figure 5-Data from Flight 14.172, flown near local midnight. Curves labeled A and D refer to ascent and descent, respectively. See text for description of the 3 sets of curves presented here. 


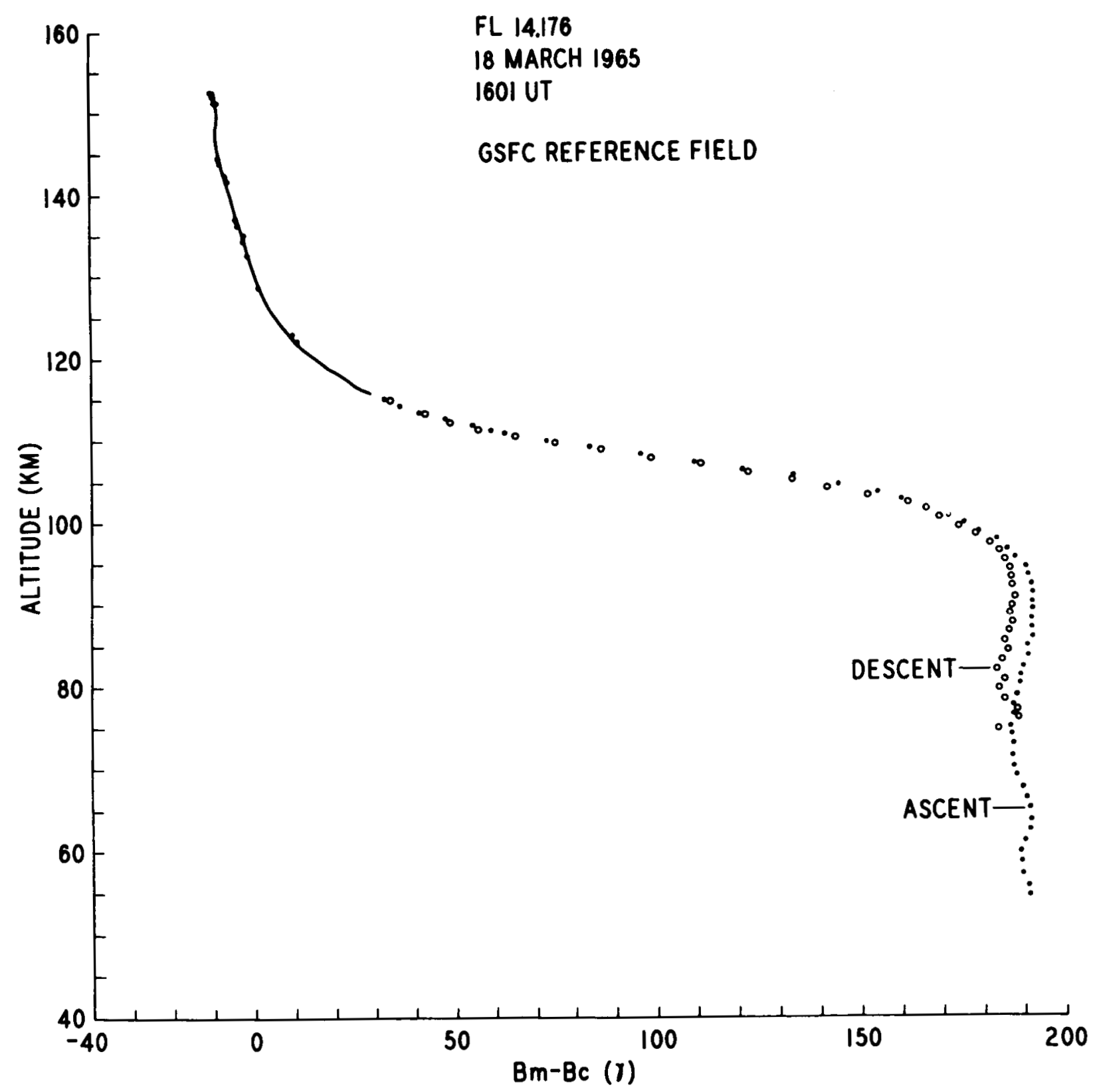

Figure 6-Data from Flight 14.176. Above altitude $116 \mathrm{~km}$ all ascent and descent data points not contained within the curve are indicated by full circles. Due to the proximity of the ascent and descent data sets, connecting curves between consecutive points are omitted. 


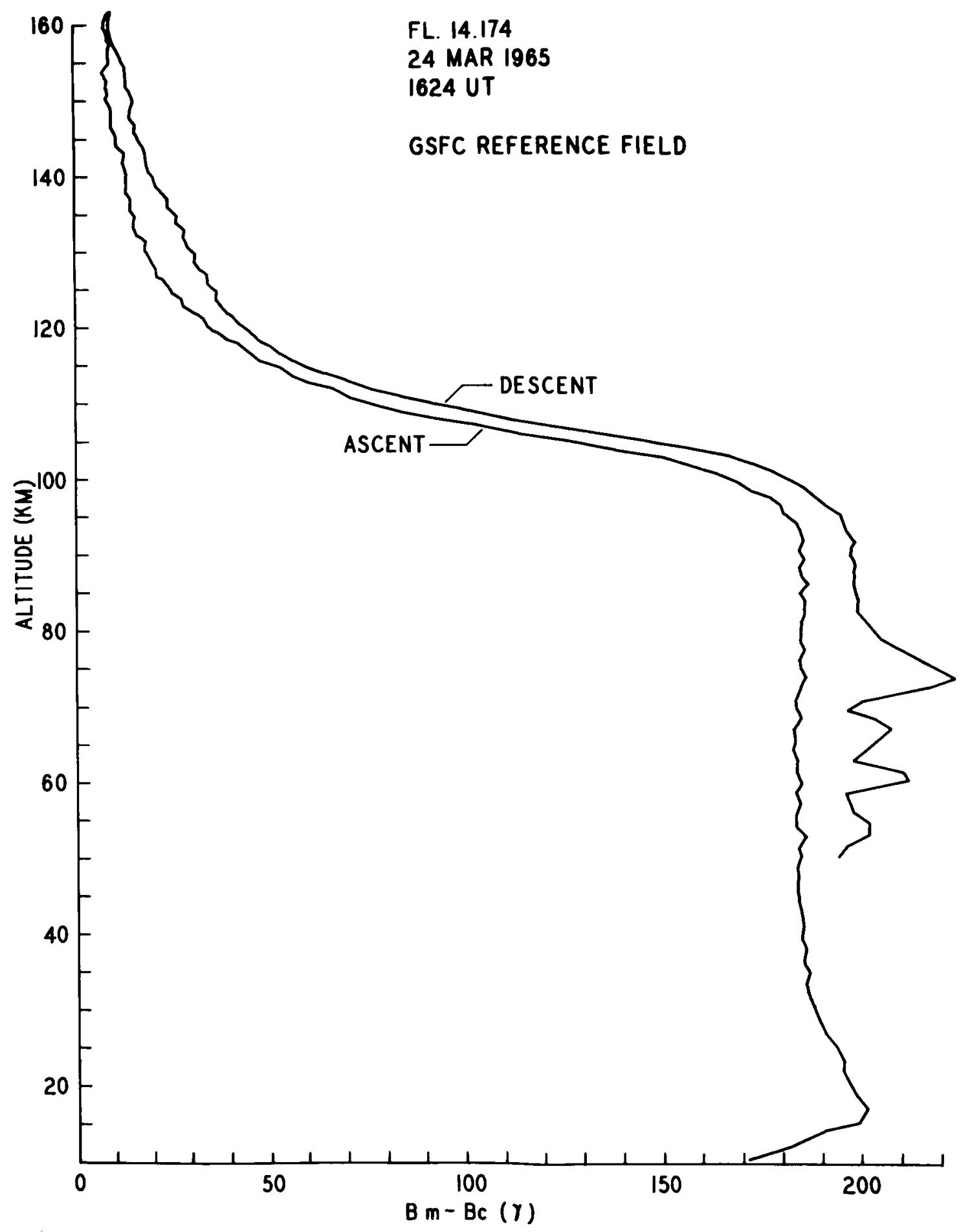

Figure 7-Data from Flight 14.174; s ee the title for Figure 3. 


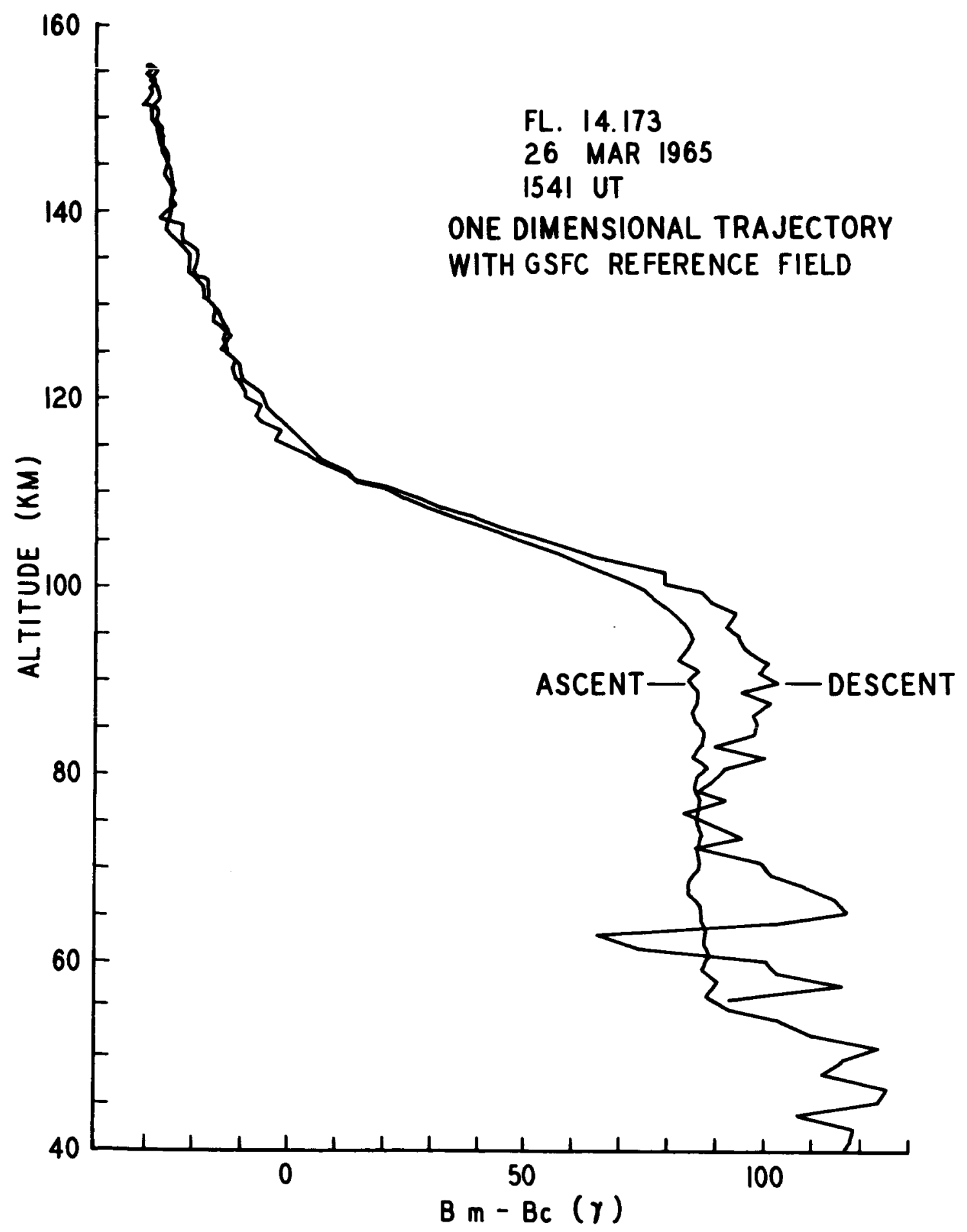

Figure 8-Data from Flight 14.173; see the title for Figure 3 and the discussion in text. 


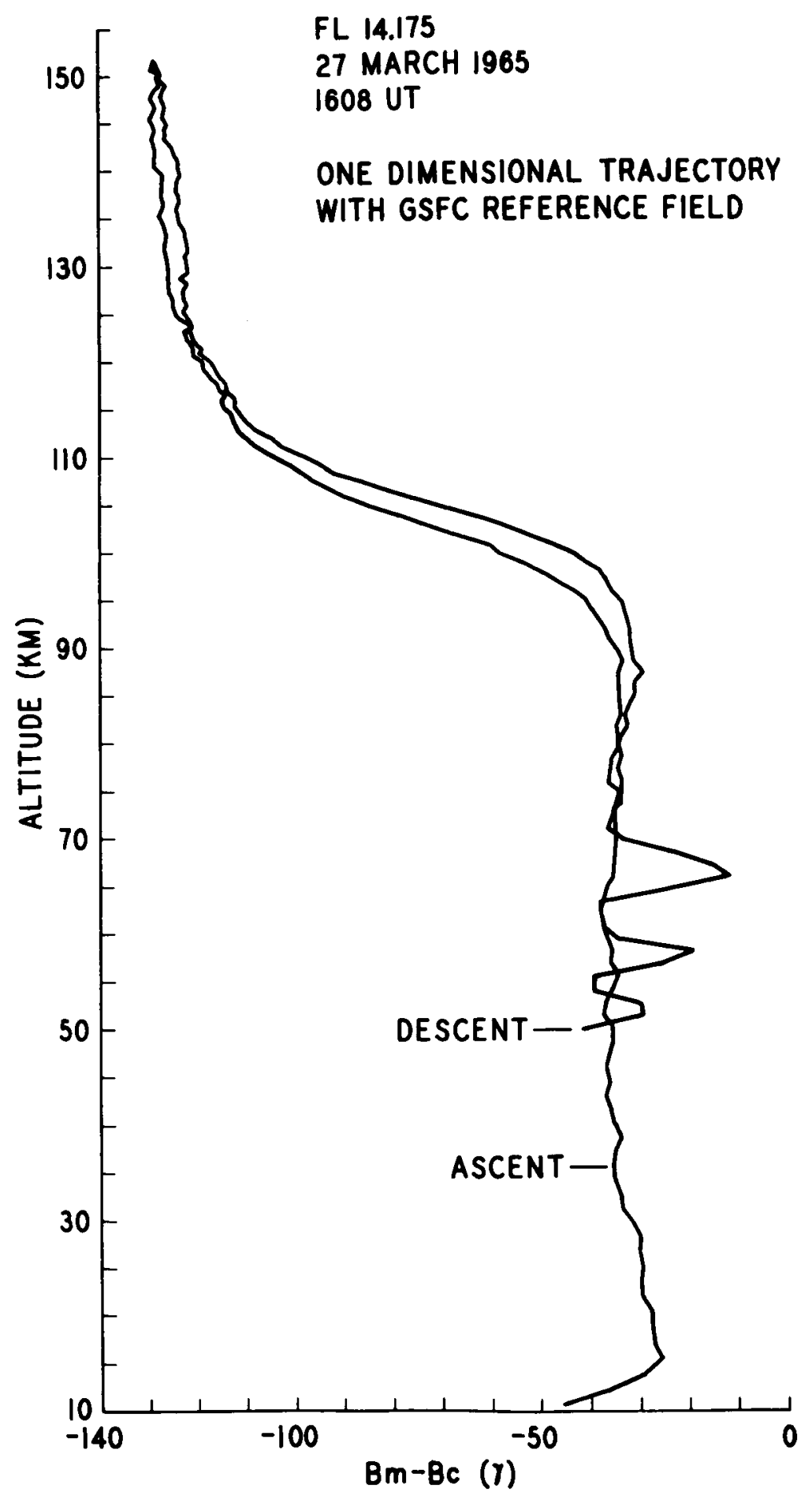

Figure 9-Data from Flight 14.175; see the title for Figure 3. 


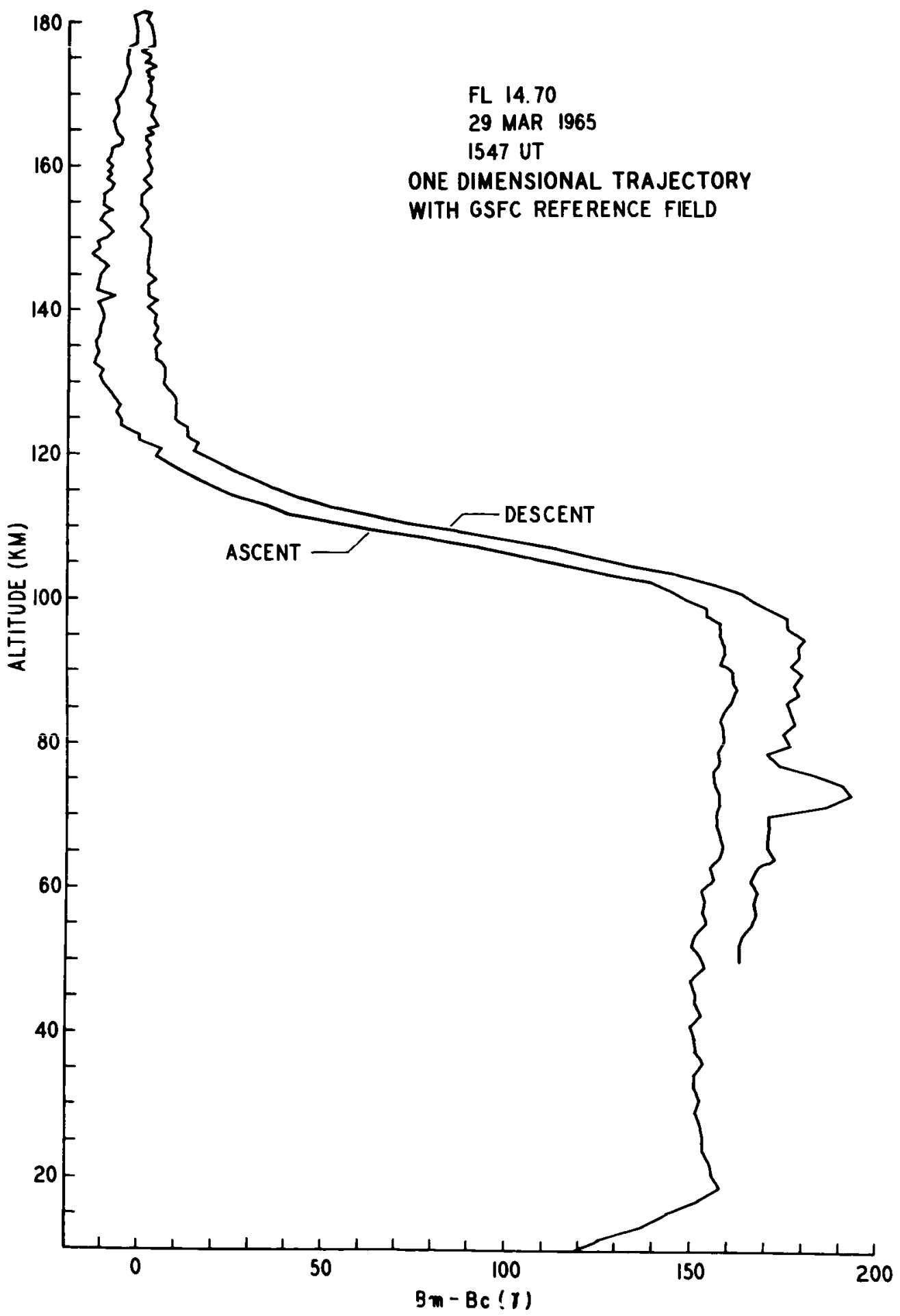

Figure 10-Data from Flight 14.70; see the title for Figure 3. 

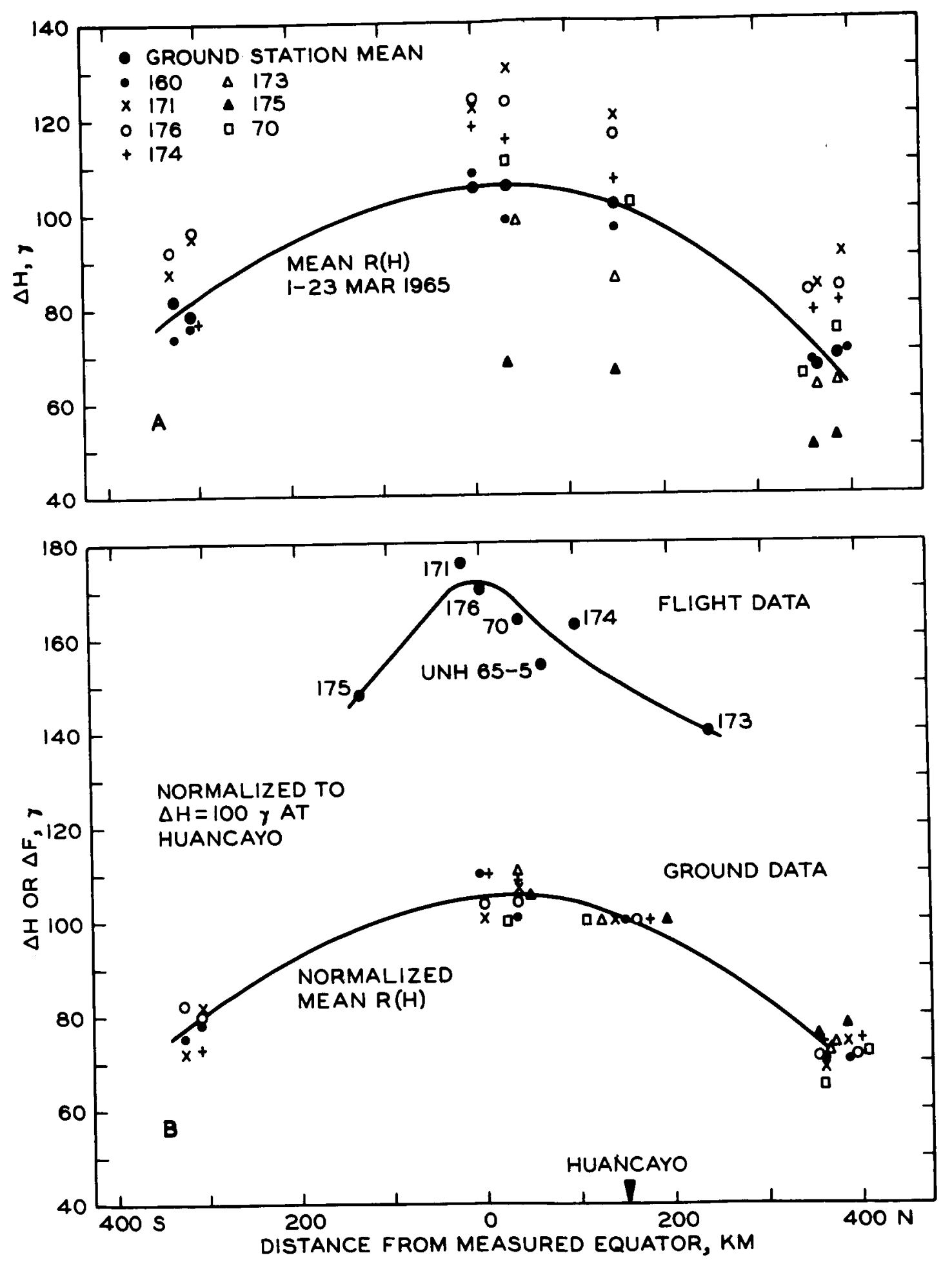

Figure 11A-The eman range $R(H)$ of the $H$ component as a function of distance north and south of the equator. The points, designated according to the key at upper left, represent instantaneous $\mathrm{R}(\mathrm{H})$ values measured at the Peruvian observatories at the mid-time of the various rocket flights; Figure 11B-The mean and instantaneous $R(H)$ values in Figure 11A now normalized to $\Delta H=100 \gamma$ at Huancayo. Similarly normalized values of $\triangle F$, the total change in scalar field measured with the rockets on their passage through the ionospheric current, are plotted at the top with a smoothedby-eye curve drown through them. 


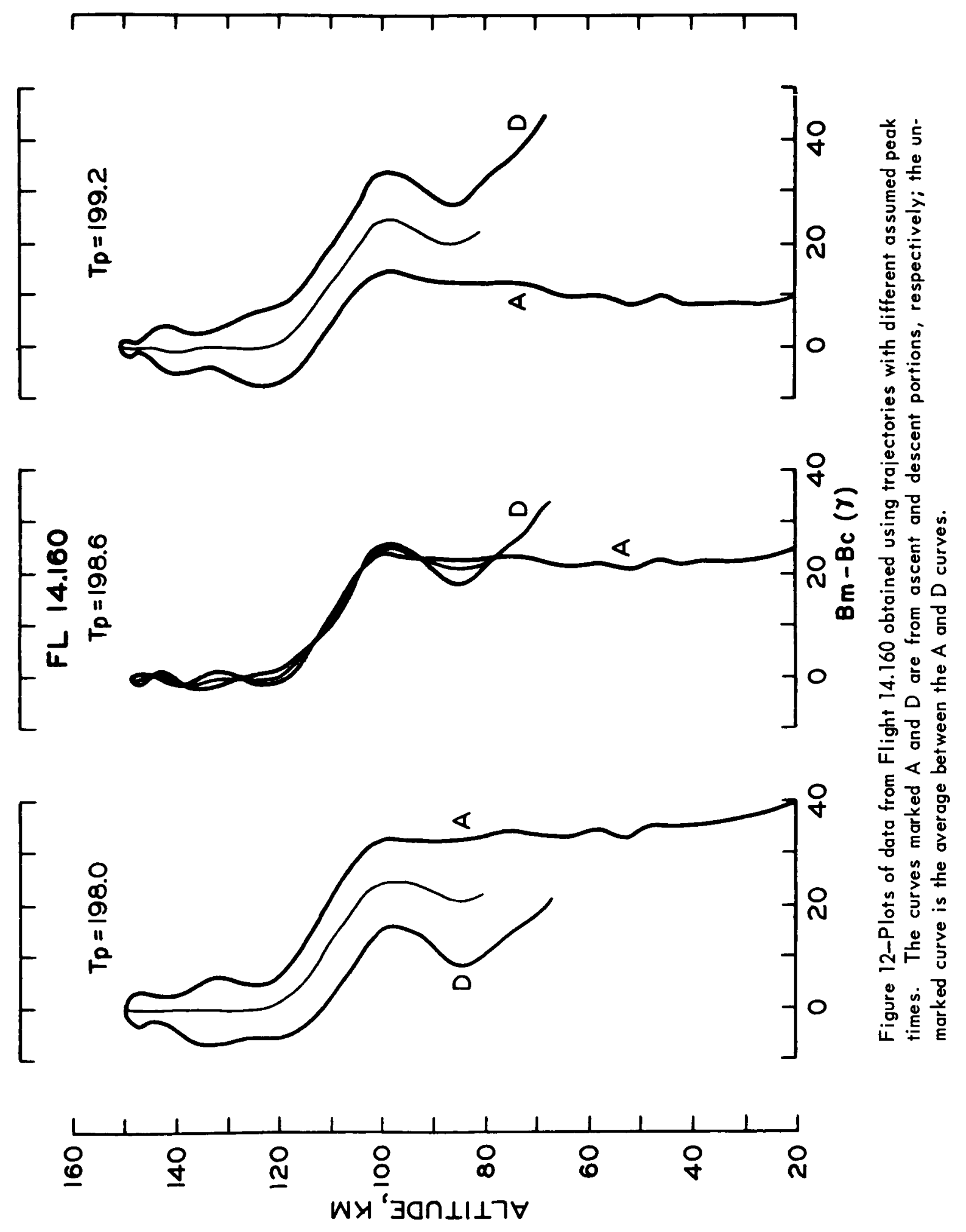



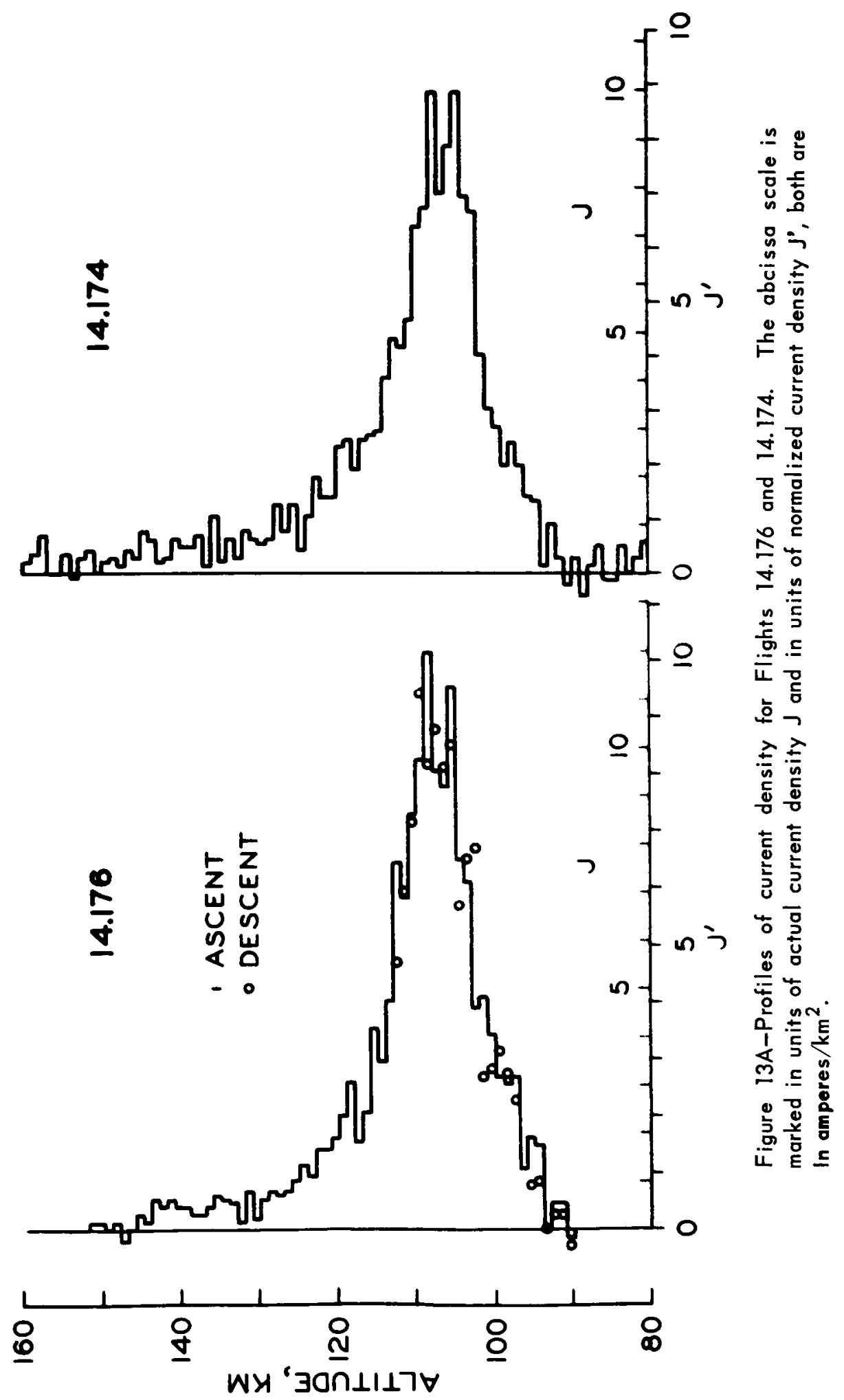

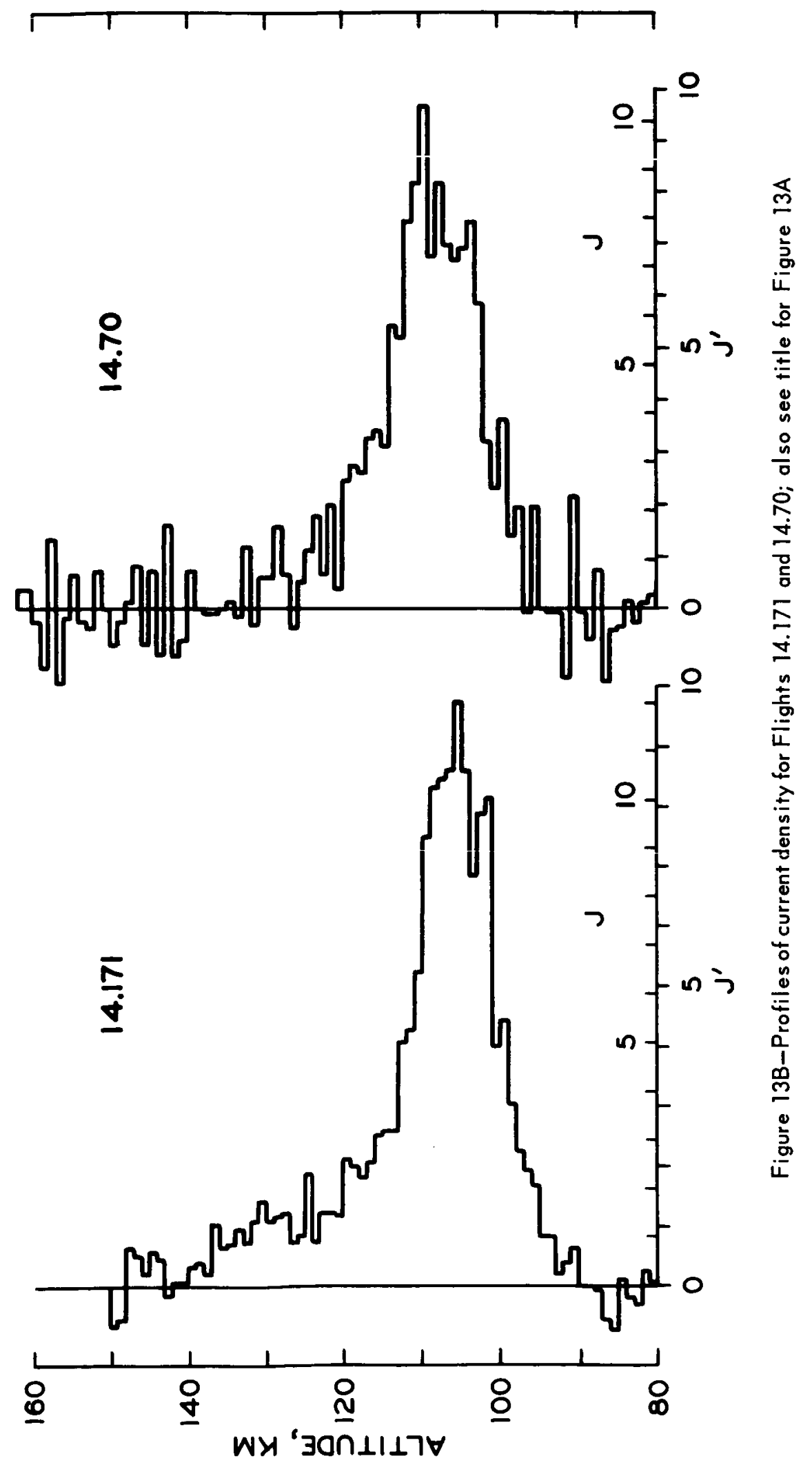


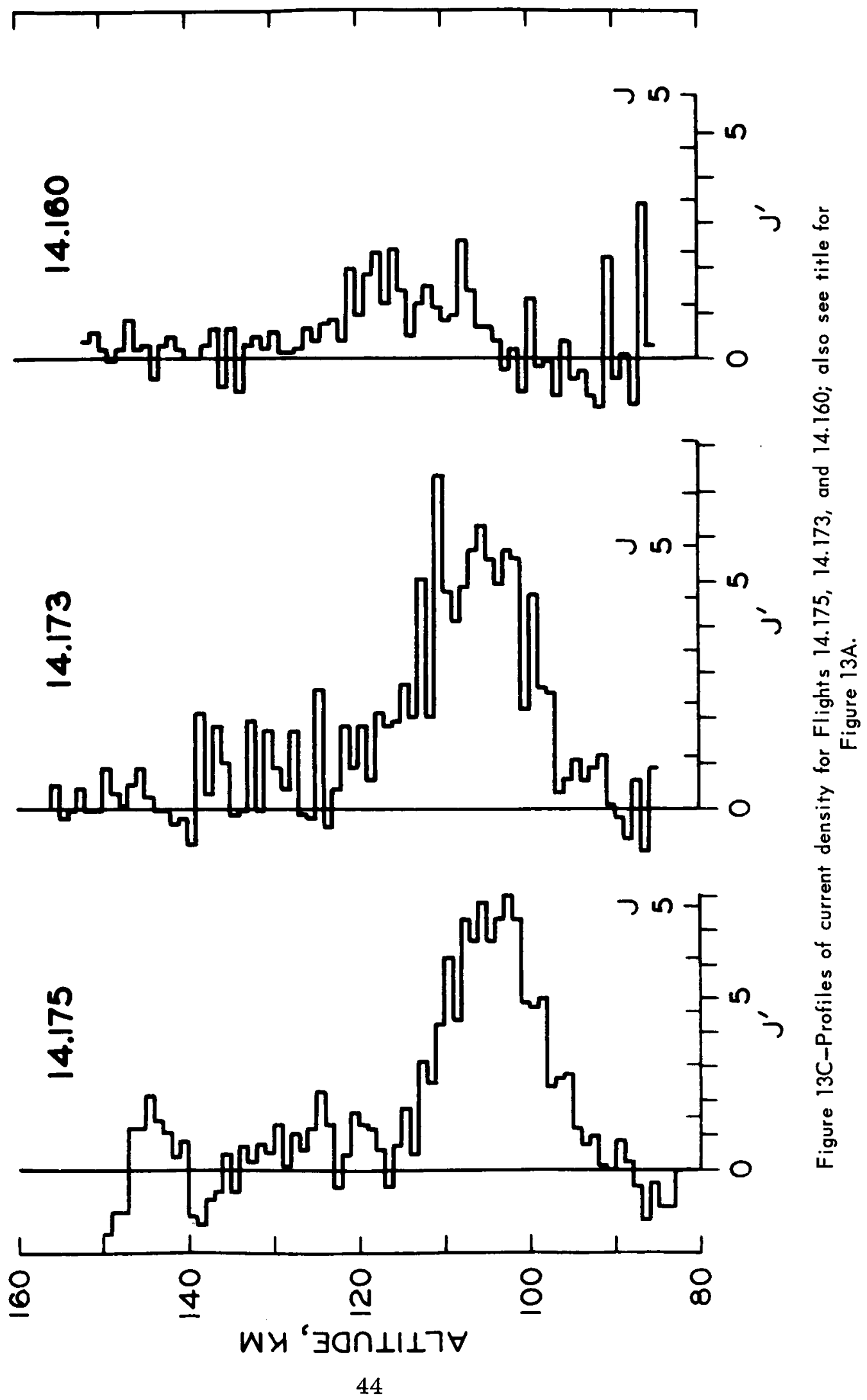




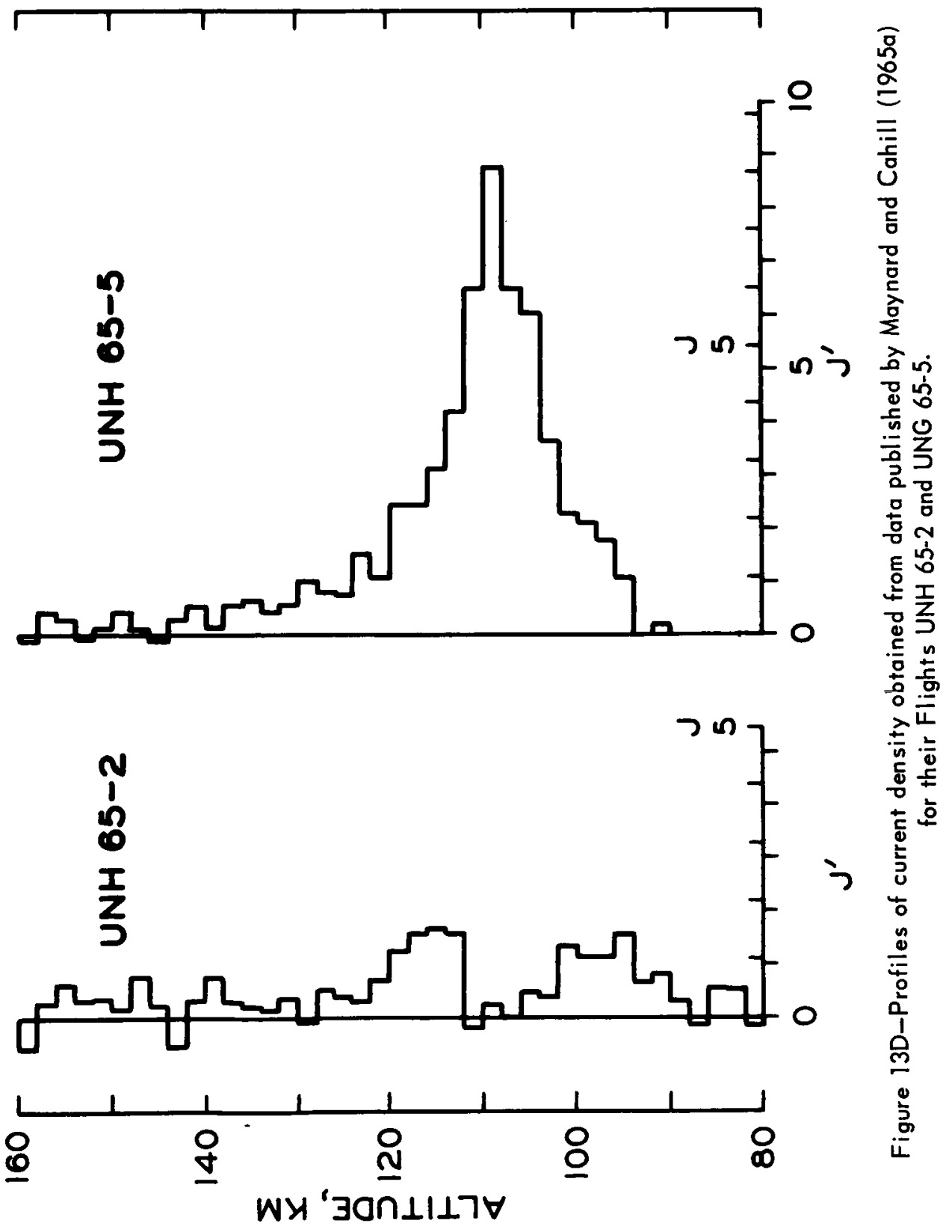




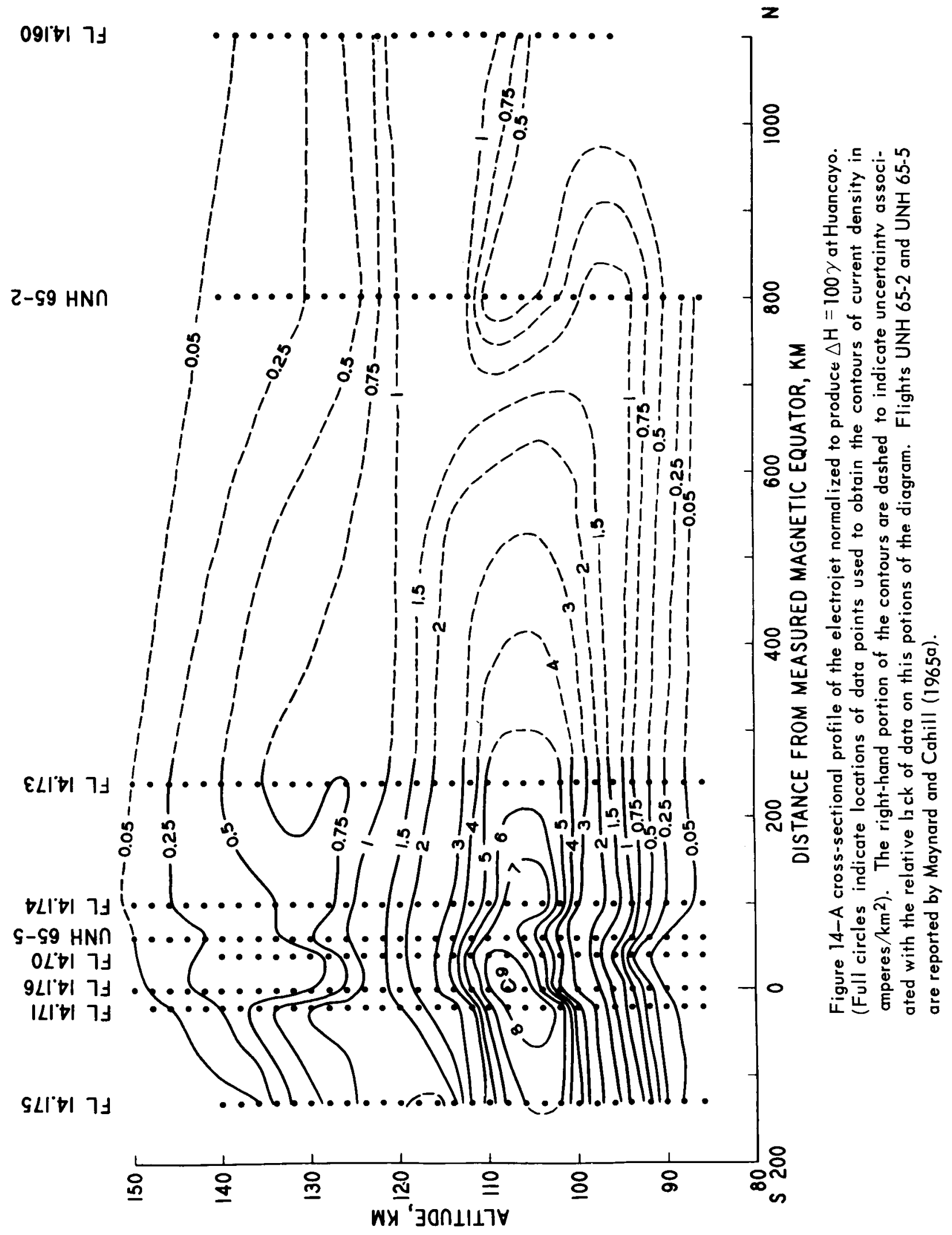

